\title{
Der mediale Diskurs über die Universitätsreformen: Journalistische Beobachtungen und professorale Selbstbeobachtungen
}

Die Reformbedürftigkeit der deutschen Universitäten wurde zur Jahrtausendwende sowohl intensiv als auch extensiv öffentlich diskutiert. Dass diese Reformprozesse durchaus unterschiedlich wahrgenommen wurden, lässt sich anhand einiger weniger medialer und professoraler Stimmen deutlich machen, die kontrastiver kaum sein könnten. Besonders anschaulich wird dies am Bereich der Lehre - und hier vor allem anhand der Diskussionen um die „Bologna“-Reformen. Schauen wir uns zunächst zwei Äußerungen aus dem Jahr 2000 an, das den Beginn unserer Medienanalyse markiert. Zuerst eine journalistische Stimme:

\begin{abstract}
„Wenn Deutschland vor den Herausforderungen der Wissensgesellschaft und der Internet-Wirtschaft bestehen will, dann muss das Studium dringend reformiert werden. Es muss praxisnäher, kürzer und flexibler werden. Diese Erkenntnis ist nicht neu, aber sie gehört heute umgesetzt, nicht morgen. “ (Thomas Kerstan, DIE ZEIT 14/2000). ${ }^{1}$
\end{abstract}

Ganz anders im Duktus ein Professor:

„Die Universität gerät zunehmend unter Druck, ihre Studiengänge von allem theoretischen ,Luxus' zu reinigen und den Bedürfnissen der Praxis anzupassen. So wie die Dinge liegen, dürfte dabei nicht viel mehr als ein Mischmasch herauskommen: ein bisschen Theorie und ein bisschen Praxis. Von da zur schlechten Theorie und schlechten Praxis ist nur ein kurzer Schritt.“ (Arnd Morkel, F\&L 8/2000, S. 398).

\footnotetext{
${ }^{1}$ Die journalistischen Beiträge aus DIE ZEIT sind dem Online-Archiv der Wochenzeitung entnommen und nicht den Printausgaben. Wir verzichten daher hier, anders als bei Beiträgen in DER SPIEGEL und in der Zeitschrift Forschung \& Lehre (F\&L), auf Seitenangaben. Eine vollständige Auflistung der in diesem Kapitel verwendeten Artikel mit Link zum jeweiligen Artikel im Online-Archiv befindet sich im Anhang dieses Kapitels.
} 
Während der ZEIT-Journalist Thomas Kerstan von „dringend“ - und zwar „heute“ und nicht erst „morgen“ - zu ergreifenden Maßnahmen spricht, sieht der emeritierte Politikwissenschaftler Arnd Morkel hierin nicht weniger als eine von außen forcierte Anpassung an die als übergriffig eingestuften Bedürfnisse der Praxis mit entsprechend negativen Konsequenzen - nicht nur - für die akademische Bildung.

Solche oftmals harten Kontraste der Einschätzungen und Bewertungen zeichnen wir in diesem Kapitel nach. Es überrascht nicht, dass die wechselseitigen Provokationen immer wieder in rhetorischen Eskalationen mündeten. Ohne hier nun Position beziehen zu wollen, wer insgesamt oder in einzelnen Punkten Recht hat, rekonstruieren wir dieses Bild einer teilweise extremen Polarisierung - die reformablehnenden ProfessorInnen auf der einen, die reformbefürwortenden JournalistInnen auf der anderen Seite - nicht zuletzt auch deshalb, um zu verdeutlichen, vor dem Hintergrund welcher medial vermittelten Stimmungslage unsere Untersuchung zu verorten ist. Man fragt sich ja unwillkürlich, ob es diese beiden unversöhnlichen Lager tatsächlich gibt und ob allen Beteiligten nichts anderes übrig blieb, als sich dem einen oder dem anderen anzuschließen. Und sofern es sie zu Beginn der Reformen gab: Haben sie sich seitdem vielleicht wieder aufgelöst?

Doch der mediale Diskurs war nicht bloß Anstoß für unsere Forschungen. Viele ProfessorInnen werden die journalistische Berichterstattung und Kommentierung der Universitätsreformen ebenso wie die Stellungnahmen aus der Kollegenschaft zur Kenntnis genommen haben. Neben den je eigenen Reformerfahrungen kann die Berichterstattung über Reformen eine weitere Quelle der Identitätsverunsicherung und -behauptung darstellen, beide also noch bestärken. Inwieweit haben die journalistischen Berichterstattungen und die öffentlichen Stellungnahmen ,aus den eigenen Reihen' auf die persönliche Sicht der Dinge abgefärbt, die ja zunächst einmal auf individuelle Erfahrungen vor Ort zurückgeht? In welchen Hinsichten neigt die eigene Sicht der einen oder der anderen Seite des medialen Diskurses zu, und wo setzt sie sich von beiden Lagern ab? Am Ende unserer eigenen empirischen Untersuchung wird sich dann zeigen, ob man die ProfessorInnen tatsächlich bis heute als geschlossene Front von Reformverweigerern einstufen kann.

Es geht uns hier nicht um eine vollständige Nachzeichnung des Diskurses. Anstelle sämtliche Stellungnahmen und Argumentationen in ihrer Gänze mit all ihren Widersprüchen, Abstufungen oder etwaigen Korrekturen darzulegen, zeichnen wir ein für unsere Untersuchungsfrage ausreichendes selektives Bild. Wie schon im Abschn. 1.3 erläutert, besteht die Datenbasis unserer Medienanalyse aus Artikeln in DIE ZEIT und DER SPIEGEL für die journalistische Betrachtung der Reformen sowie aus von ProfessorInnen verfassten Beiträgen 
in der Zeitschrift Forschung und Lehre (F\&L) für deren Sicht. Ausgewertet werden die Jahrgänge 2000 und 2001 für den Beginn der Reformen sowie 2012 und 2013 für eine Bilanzierung nach zehn Jahren der Reformumsetzung. ${ }^{2}$ Die übergreifende Frage an dieses empirische Material lautet: Was waren in beiden Zeiträumen und aufseiten beider BeobachterInnen des Reformgeschehens Journalisten hier, Professorinnen dort - die dominanten Deutungsmuster in Gestalt von Einschätzungen und Bewertungen dieses Geschehens?

Wir beginnen mit „Bologna“ als derjenigen Reform, die die größte mediale Aufmerksamkeit erfahren hat - allein schon deshalb, weil ein immer größer gewordener Anteil der Bevölkerung, entsprechend der von Kohorte zu Kohorte gestiegenen Studierendenquote, von dieser Thematik unmittelbar betroffen ist. Wir schildern hierzu zunächst für beide Zeiträume die medial zum Ausdruck gebrachte Fundamentalverweigerung der ProfessorInnen (Abschn. 2.1), anschließend die in den Jahren 2000 und 2001 artikulierten „Bologna“-Hoffnungen der JournalistInnen, angesichts derer die professorale Haltung als ,ewig gestrige Fortschrittsverweigerung erscheint (Abschn. 2.2). Diese den HochschullehrerInnen zugeschriebene Attitüde wurde von journalistischer Seite dann auch bei weiteren Reformen ausgemacht: bei der W-Besoldung und der Stärkung der Universitätsleitungen als Komponenten des ,New Public Management" (NPM) sowie bei der Einführung der Juniorprofessur. Der Tenor war: Man muss den ProfessorInnen ,Beine machen“ (Abschn. 2.3). Im Vergleich dazu fällt die Sicht der journalistischen BeobachterInnen auf die Reformprozesse zehn Jahre später differenzierter aus: Auf der einen Seite wird weiterhin als nötig erachtet, bei den ProfessorInnen durch Wettbewerbsdruck Spreu von Weizen zu trennen und eine verantwortungslose Autonomie unter Kontrolle zu bringen; auf der anderen Seite werden aber auch zunehmend Probleme eines überbordenden Wettbewerbsdrucks und einer Unterfinanzierung der Universitäten gesehen (Abschn. 2.4). Die journalistische Berichterstattung korrigiert sich also ein Stück weit selbst. Die medial zum Ausdruck kommende professorale Beobachtung der Reformprozesse sieht sich hingegen über die Zeit bestätigt: Was 2000 und 2001 noch Befürchtung war, hat sich zehn Jahre später nicht nur hinsichtlich „Bologna“, sondern auch bezüglich „Exzellenzinitiative“ und NPM bestätigt - weshalb eine fortgesetzte Verweigerung nur konsequent ist (Abschn. 2.5). Mit Blick auf unsere eigene

\footnotetext{
${ }^{2} \mathrm{Da}$ das erste gesamtdeutsche Hochschul-Ranking, veröffentlicht in DER SPIEGEL im Jahr 1999, nicht nur große mediale Aufmerksamkeit erlangte, sondern vor allem auch Anlass zur kritischen Auseinandersetzung mit der Studiensituation an deutschen Universitäten gab, werden wir Ausgaben dieses Jahrganges ergänzend hinzuziehen.
} 
Untersuchung interessiert uns an diesem medialen Diskurs, inwieweit er die je individuelle professorale Reformerfahrung vor Ort widerspiegelt und präformiert. Zeigt er, wo der Schuh drückt? Und prägt er umgekehrt die Erfahrung, wo der Schuh als drückend empfunden werden sollte (Abschn. 2.6)?

\subsection{Schreckgespenst „Bologna“: Die durchgängige professorale Perspektive auf die Studienstrukturreform}

Die Perspektive der Professorinnen und Professoren auf die Studienstrukturreform kennzeichnete in den Jahren 2000 und 2001 eine recht eindeutige ablehnende - Haltung. Einige Beiträge in F\&L genügen zur Illustration der zentralen Kritikpunkte.

\section{Ökonomisierung}

So spricht sich Hartmut Schiedermair im Jahr 2001, zu diesem Zeitpunkt Präsident des Deutschen Hochschulverbandes (DHV), in einer Art Rundumschlag gegen die Ökonomisierung der Wissenschaft und gegen eine nützlichkeitsorientierte, an Effektivitäts- und Effizienzanforderungen ausgerichtete Lehre aus. Der Rechtswissenschaftler ist schon qua Amt medial stark präsent. Seine Kritik am Aufkommen einer ökonomisierten Semantik der „Humanressourcen“ und „-kapitale“ gibt die Folgen eines solchen verschlankten Studiums zu bedenken: „schmale[] Intelligenzen, die zwar leicht verfügbar, jedoch von der Kreativität ebenso weit entfernt sind wie von der Fähigkeit, den Aufbruch in das Neue zu wagen." (Schiedermair, F\&L 05/2001, S. 237)

Ein Jahr zuvor griff der bereits erwähnte emeritierte Politikwissenschaftler Morkel (F\&L 8/2000) die angekündigte Neuausrichtung der universitären Kernaufgaben in Richtung Praxis- und Anwendungsorientierung von Forschung und Lehre an. Seine Sorge gilt dem schützenswerten genuin universitären Charakter von Studium und Lehre. Er stehe zur Disposition, wenn die akademische Ausbildung sich den nicht-wissenschaftlichen Zwängen beuge und so zum „Bestandteil einer riesen Ausbildungsmaschinerie“ (ebd., S. 398) verkomme:

„[D]ie Universität [dient] der Praxis nur dann, wenn sie ihre theoretischen Bemühungen nicht vernachlässigt, wenn sie mehr als das unmittelbar Nützliche lehrt; mit einem Wort, wenn sie mehr als eine bloße Berufsschule ist. [...] Der Nutzen der Universität ist abhängig von einer Substanz, die auf dem Wege einer bloß auf das Nützliche reduzierten Ausbildung nicht erworben werden kann." (ebd.) 
Morkel geht es um die Verteidigung der Lehrinhalte gegen eine um sich greifende Effizienz- und Praxiserwartung, die die theoretischen Grundlagen einer Disziplin als im Grunde entbehrlichen „Luxus“ (ebd.) begreife und damit den praktischen Erfordernissen des Arbeitsmarktes nachordne. Hier zeigt sich nicht nur ein Dissens in Bezug auf das Ausmaß des als erforderlich erachteten Praxisbezugs. Dieser wird vielmehr einer fundierten wissenschaftlichen Ausbildung als konträrer Zielgröße der Lehre entgegengestellt; und nicht weniger als die Bedeutung der Universität als „Zone der Wahrheit“ (ebd.), wie Morkel den Philosophen Josef Pieper zitierend anmerkt, gerate bei einer Zielverschiebung in Gefahr. In ähnlichem Duktus verweist auch der Anglist Theo Stemmler (F\&L 2/2000, S. 85) auf die Gefahr, dass die Universität - sollten die beschriebenen Entwicklungen voranschreiten - ,,vor lauter Nützlichkeit“ am Ende „unnütz“ würde, man zukünftig daher ,den Begriff ,Universität“ streichen und durch ,Höhere Berufsschule" ersetzen“ müsse.

Ist in den Äußerungen von Schiedermair, Morkel und Stemmler noch nicht explizit von „Bologna“ die Rede, müssen sie dennoch vor dem Hintergrund der damaligen Reformankündigungen und der anhaltenden Diskussion um einen als mangelhaft angesehenen Praxisbezug der akademischen Ausbildung gelesen werden.

\section{, Verfachhochschulung ‘}

In dieselbe Richtung verweisen auch professorale Meinungsäußerungen, die sich der befürchteten Erosion der Grenzen zwischen Fachhochschulen und Universitäten widmen. So veranlasste ein Positionspapier der Landesrektorenkonferenz der Fachhochschulen des Landes Nordrhein-Westfalen im Februar 2000 die dortigen Universitäten dazu, hier vertreten durch den gerade aus dem Amt scheidenden Vorsitzenden der Landesrektorenkonferenz der Universitäten, Jens Peter Meincke, ihr Selbstverständnis in dezidierter Abgrenzung zu formulieren: Während die Fachhochschulen ,mit erheblicher Unterstützung der Politik auf eine Einebnung der Unterschiede [...] [drängten]“" (Meincke, F\&L 12/2000, S. 631), wird die ,unterschiedliche Ortsbestimmung“ (ebd.) beider Typen durchdekliniert - das Fazit:

„Die Universitäten sind Einrichtungen, in denen Forschung und Lehre ineinandergreifen und sich wechselseitig durchdringen, nicht Ausbildungsstätten, die zur Unterstützung der Ausbildung oder unabhängig von ihr auch Forschung betreiben. [...] Die Fortentwicklung der Wissenschaft durch Entdeckung des bisher Unbekannten und durch vertieftes Verständnis des bereits Bekannten im ständigen Austausch mit dem wissenschaftlichen Nachwuchs und mit den Studierenden ist die zentrale Aufgabe der Universitäten.“ (ebd., S. 632) 
Die diskutierte Angleichung beider Hochschultypen bzw. die geforderte höhere Durchlässigkeit in beiden Richtungen wird mit Verweis auf die unterschiedlichen Zielvorgaben - Forschungsorientierung hier, primäre Anwendungsorientierung dort - auf universitärer Seite entschieden abgelehnt.

Die Äußerungen dieses Zeitraumes weisen folglich oftmals den Charakter einer Grundsatzkritik auf, der auch durch das unvorhersehbare Reformausmaß und seine Folgen geformt wird. Zwar waren die Reformmaßnahmen in Sachen „Bologna“" politisch beschlossene Sache, ${ }^{3}$ ihre Umsetzung steckte aber größtenteils noch in den Kinderschuhen. Folgerichtig wurde in den Jahren 2012 und 2013 die anhaltend kritische Haltung der ProfessorInnen dann konkreter $\mathrm{zu}$ den bereits vollzogenen Studienstrukturreformen in Beziehung gesetzt. Befürchtungen, die sich bewahrheitet haben, aber auch nicht geahnte negative Folgen dominieren die Inhalte der einschlägigen Beiträge in F\&L.

So stellt die Politikwissenschaftlerin Kerstin Odendahl (F\&L 11/2012, S. 882) nüchtern fest: „Die Bildung ist ökonomisiert worden.“ Auch der Soziologe Wolfgang Ludwig-Mayerhofer geht 2012 von einer längst vollzogenen Transformation des universitären Studiums durch die „Bologna“-Reform aus:

„Es [das universitäre Studium] hat sich von einer Einrichtung, die den Erwerb von Wissen, Einsicht und Reflexionsvermögen ermöglichen soll, in einen Parcours verwandelt, auf dem es gilt, möglichst effizient, und das heißt: mit dem geringstmöglichen Aufwand, Punkte zu sammeln, mögen diese nun (fälschlich) Kreditpunkte, Leistungspunkte oder einfach ECTS-Punkte genannt werden. [...] Wird immer wieder beklagt, dass Studierende nicht mehr Erkenntnis um der Erkenntnis willen anstreben, sondern Lehrveranstaltungen nur noch mit Blick auf die Arbeitsmarktgängigkeit des zu erwerbenden Wissens beurteilen würden, so mag das vor ein paar Jahren noch so gewesen sein; heute geht es ihnen aber nur noch darum, dass der workload für den Erwerb der Punkte auf keinen Fall zu hoch sein darf, während die Inhalte mit immer größerer Gleichgültigkeit betrachtet werden." (LudwigMayerhofer, F\&L 10/2012, S. 785).

Kritisierten Morkel und Schiedermair noch einen durch die Studienreformen forcierten Utilitarismus, geht es in Ludwig-Mayerhofers Beitrag schon gar nicht mehr um zur Disposition stehende Ideale wie Zweckfreiheit, Autonomie oder Kreativität. Nicht die inhaltliche Ausrichtung der Lehre an der Praxis bzw. den Anforderungen des Arbeitsmarktes, sondern die Zielverschiebung hin zu einem

\footnotetext{
${ }^{3}$ Auf die von Italien, Frankreich, Deutschland und Großbritannien unterzeichnete „Sorbonne“-Erklärung (1998) zur Einigung über eine gemeinsame Hochschulpolitik folgte ein Jahr später die gemeinsame Erklärung der europäischen Bildungsminister zum „,europäischen Hochschulraum“, die „Bologna“-Erklärung (1999).
} 
reinen Punkteerwerb sei mittlerweile das problematische Resultat der Reformen. Dieses „Diktat des Punktesammelns“ (ebd.) nehme zuweilen absurde Züge an:

„Lehrveranstaltungen, die nicht in das Punkte-Raster fallen - sprich: die keinem Modul zugeordnet werden können -, werden von Studiendekanen aufgespürt und ausgemerzt. Eine Heerschar von Hilfskräften unterstützt Studierende, Administrationen und Lehrende darin, den Dschungel der Studienordnungen so aufzubereiten, dass es trotz aller Konfusion der Studiengänge möglich ist, diese in der vorgeschriebenen Regelstudienzeit zu durchwandern. Denn schließlich erhalten die Universitäten höhere (,leistungs'-orientierte) Mittel zugewiesen, wenn das Studium in der Regelzeit absolviert wurde, gleichgültig, wie befähigt die Absolventen tatsächlich sind. Dieses ,Bologna 'ist nicht tot, es ist nicht einmal im Absterben begriffen - und wir werden es auch nicht mehr loswerden. Denn es hat den Kreislauf und den Stoffwechsel der Universitäten so modifiziert, dass bereits ein neuer Organismus entstanden ist, der mit der alten Universität nichts mehr gemein hat.“ (ebd.)

Zur Gleichgültigkeit gegenüber den $\mathrm{zu}$ vermittelnden und $\mathrm{zu}$ erlernenden Inhalten durch die „Bologna“-Reform kommen also in dieser Deutung die problematischen Effekte der leistungsorientierten Mittelverteilung (LOM) hinzu.

Es sind nicht wenige Beiträge, die in generalisierter Weise mit „Bologna“ einen bereits vollzogenen Wandel verbinden, der eindeutig negativ bewertet wird: „Zahlenmäßig irgendwie auf[zugehen]“ sei mittlerweile zur „Hauptsache“ eines Studiums geworden, so der Soziologe Stefan Kühl (F\&L 04/2012, S. 293); und der Erziehungswissenschaftler Norbert Seel (F\&L 12/2012, S. 1001) stellt die Beobachtung an, dass selbst „Studierende [, die] mit viel Enthusiasmus und Fähigkeit zum selbstständigen Denken an die Universitäten kommen, [...] sie am Ende als Konformisten [...] verlassen“. Was dies konkret für die eigene berufliche Praxis bedeutet, wird von den ProfessorInnen ebenfalls dargelegt. „Zeitdruck und -not, alles in einem vorgefassten Plan durchlaufen zu müssen“, so der Erziehungswissenschaftler Klaus Zierer im Jahr 2012, prägten mittlerweile die Arbeitssituation und ließen kaum mehr „Zeit für Gespräche, für Vertiefung und Besinnung"; und Arbeitsmarkterfordernisse und Zielvereinbarungen potenzierten das ohnehin überzogene Wettbewerbsstreben, das schon jetzt „das Leben in all seinen Facetten dominier[e]" (Zierer, F\&L 12/2012, S. 1000).

Es sind gerade auch ältere, teils emeritierte ProfessorInnen, die sich sorgenvoll zu den Reformfolgen äußern. ${ }^{4}$ Aus der Perspektive eines Professors, der seine

\footnotetext{
${ }^{4}$ Dass Interessenwahrung das vordergründige Motiv der professoralen Kritik sei und ProfessorInnen einfach ,keine Lust“ hätten, sich auf „Bologna“ einzulassen, wie ein in Politik und Medien formulierter gängiger Vorwurf lautet, wird durch diese Stimmen entkräftet.
} 
eigene „Lebenszeit“ zu einer Zeit habe „verbringen dürfen, als die Freiheit und Ungebundenheit der wissenschaftlichen Forschung und der Lehre noch als Leitlinie über der deutschen Hochschule stand", spricht ein Emeritus resigniert gar von einem „Verlust des Elementarsten, was Hochschule ausmacht“:

„[D]as direkte und spontane Zugehen auf die Zielgruppe all unserer Tätigkeit, nämlich auf unsere Studenten und Hörer. Sie sollen etwas erleben und mitgerissen werden, nicht in die Vergangenheit, sondern in die wahren Probleme der Gegenwart und der Zukunft. Stattdessen machen sich Verschulung, festgezurrte immer neue Lehrpläne, Parallelstudiengänge, Trennung von Forschung und Lehre, die in Wirklichkeit längst stattgefunden hat, breit. Ja, ich meine ,Bologna'. Ja, ich meine angedachte Forschungsuniversitäten!“ (anonym, F\&L 02/2012, S. 116).

\section{,Bürokratismus ‘}

Ein zeitaufwendiger, oft als sinnlos angesehener überbordender ,Bürokratismus“ bildet wiederkehrend das Zentrum „Bologna“-kritischer Beiträge. Während im obigen Zitat als eigentlich Leidtragende der Reformen die Studierenden benannt werden, steht hinter dieser Klage nicht zuletzt die durchlebte oder potenziell eintretende Einschränkung der professoralen Autonomie. An die Stelle eines Arbeitsbündnisses zwischen Lehrenden und Studierenden, in dem das Ideal einer forschungsbasierten ,lebendigen ' Lehre realisiert wird, trete nun ein ,festgezurrte[r]“ Lehrplan. Diesem Argument folgt auch der Beitrag des Germanistik-Professors Klaus Bayer (F\&L, 01/2013, S. 36), der der „Bologna“"-Reform eine „Zerstörung der geisteswissenschaftlichen Prüfungskultur" vorwirft. Bayer bezweifelt nicht nur die Sinnhaftigkeit der reformierten Prüfungsmodalitäten und skizziert Auswirkungen wie eine Inflation guter Noten als Resultat unangemessener, eng getakteter Prüfungsvorgaben. Darüber hinaus sieht er sein eigenes Rollenverständnis als Lehrender angesichts veränderter, gar „demütigende[r]“ Anforderungen an diese Tätigkeit bedroht:

„Ich habe es als demütigenden Rückschritt empfunden, dass mit der ,Bologna“Reform diese sorgfältige Beratungs- und Prüfungstätigkeit durch eine Flut kurzer, bürokratisch geregelter, überwiegend anonymer Einzelprüfungen abgelöst wurde und dass eine unsinnig feingestufte und inhaltlich nicht explizite Benotung an die Stelle fruchtbarer Gespräche mit Studierenden und Kollegen trat. Ich bin gewiss nicht der einzige Hochschullehrer, dessen Prüfungsmotivation unter dem Eindruck gelitten hat, dass er nun nicht mehr als gesprächserfahrener, kompetenter und um Gerechtigkeit bemühter Prüfer, sondern nur noch als Rädchen im Getriebe gebraucht wird." (Bayer, F\&L 01/2013, S. 38). 


\section{De-Professionalisierung}

Strikte Leistungsvorgaben, die an die Stelle situativ vollzogener, individueller und ,sorgfältiger" Betreuung getreten seien, werden als Abwertung der eigenen beruflichen Erfahrung erlebt. Die restriktive Gestaltung der Lehrpraxis wird in dieser Lesart mit einer Entwertung der Professionalität der Lehrenden gleichgesetzt. Dass der Germanist Bayer sich ,nur noch als Rädchen im Getriebe“ vorkommt, versinnbildlicht geradezu die erwachsenden Gefühle der Ohnmacht angesichts der „Flut“ an Vorgaben und Regularien. Die technisch entlehnte Wortwahl bringt das Unbehagen gegenüber der neuen ,technokratischen“ Organisation des LehrLernprozesses plastisch zum Ausdruck.

Mit entsprechenden Metaphern wird in weiteren Beiträgen das Gefahrenpotenzial eines falsch verstandenen Bildungsauftrages aufgezeigt und der klassische Humboldtsche Bildungsbegriff dem falschen Ziel großer abzuarbeitender Studierendenmassen, die schnell und effizient fit für den Arbeitsmarkt gemacht werden sollen, entgegengesetzt. So glichen Universitäten unter dem Primat des Nützlichkeitsprinzips mehr und mehr, ,pseudo-nutzenmaximierende[n] Lernmaschinen“, wie die Politikwissenschaftlerin Barbara Zehnpfennig (F\&L 10/2012, S. 797) diagnostiziert, oder verkümmerten zu „Fertigungsstraßen“ so der Wortlaut im Plädoyer „Hochschulen sind keine Fertigungsstraßen!“ des Hamburger Universitätspräsidenten und Vizepräsidenten der Hochschulrektorenkonferenz Dieter Lenzen (F\&L 05/2012); „Bildung für alle“ würde in ein „Billig für alle!“ (ebd., S. 356) verkehrt. Der Soziologe Thomas Loer (F\&L 04/2012, S. 289) bedient sich mit dem Begriff der „Massenfertigung“ einer ähnlichen Metapher:

„Die Aufgabe der Universität wird in ,Massenfertigung gesehen. Unbeantwortet bleibt die Frage, wie ohne Wissenschaft als sachlichen Kern der Universität [...] etwas hervorgebracht würde, das unterrichtet werden könnte.“

Immerhin geht Loer, anders als etwa Ludwig-Mayerhofer, der ja in skeptischer Weise bereits von der Universität als einem ,neue[n] Organismus“ sprach, von keiner Irreversibilität dieses Prozesses aus. Zumindest einige bildungspolitische Akteure gestünden inzwischen eine fehlerhafte Reformumsetzung ein. Beinahe optimistisch und mit erkennbarer Entschlossenheit äußert er sich dann auch zu den notwendigen Konsequenzen:

„So ist neuerdings in der verantwortlichen Politik die Rede davon, dass die Wissenschaft - so etwa unlängst der baden-württembergische Ministerpräsident - ein eigenes Leitbild brauche, ,das sich nicht einfach an Unternehmen orientiert, die 
bekanntlich in der Marktwirtschaft vornehmlich nach Rentabilitätsgesichtspunkten arbeiten', und Bildungsministerin Schavan konstatierte kürzlich: ,Es ist an der Zeit, eine neue gesellschaftliche Debatte über den Wert und das Wesen von Bildung zu beginnen, und zwar unabhängig von ihrer Verwertbarkeit auf dem Arbeitsmarkt. Eine späte Einsicht, fürwahr: Der beste Zeitpunkt für diese Debatte wäre vor ,Bologna' gewesen; der zweitbeste Zeitpunkt ist jetzt.“ (ebd.)

Das Urteil seines Fachkollegen Georg Kamphausen (F\&L 2/2013) fällt deutlich pessimistischer aus. Erzürnt über den Dilettantismus der Bildungspolitiker rekurriert seine Kritik auf das in medialen Diskussionsbeiträgen prominent platzierte Argument des Humboldtschen Bildungsideals, das alle bisher angesprochenen Kritiken bündelt. Wissenschaftlichkeit und Zweckfreiheit wichen dem „Grundsatz vom Praxisbezug“ (ebd., S. 116), der die Universitäten vom Heimatort der „Bildung um ihrer selbst willen“ (ebd., S. 114) zum „verlängerte[n] Arm nützlichkeitsorientierter bürgerlicher Interessen“ degradiere. Mit unverkennbarer Polemik ruft er dazu auf, der ,lustvoll betriebenen Ruinierung der Geisteswissenschaften und der Universitäten" (ebd., S. 117) durch die Reformprotagonisten die „Leitidee der Institution Universität“ entgegen zu setzen. Andernfalls wisse er nicht, wie bzw.

„,wer in einer nahezu vollständig ent-akademisierten Universität einen akademischen Ansprüchen genügenden Unterricht erteilen [soll], der über das Niveau von Volkshochschulkursen hinausgeht? [...] Wenn eine Universität mehr leisten soll als Ausbildung (nämlich Bildung) [...], dann möchte man gerne genauer wissen, was sich die neuen Bildungsliebhaber (die in den letzten Jahren das Bildungsideal Humboldts lächerlich gemacht haben) unter ,Bildung durch Wissenschaft` im Zusammenhang der sogenannten Hochschulreform denn vorstellen." (Kamphausen, F\&L 2/2013, S. 116/117).

In Kamphausens Perspektive ist eine den akademischen Selbstansprüchen genügende Lehrtätigkeit kaum mehr möglich. Zeugte Morkels zitierte Äußerung noch von der Besorgnis eines drohenden Qualitätsverlusts des universitären Studiums, erklärt Kamphausen 13 Jahre später die Universitäten für bereits „nahezu vollständig ent-akademisiert“. Seinen Vergleich mit den Volkshochschulen, deren Ausbildungsanspruch dem jetzigen universitären nur noch unwesentlich nachstünde, nennen wir hier stellvertretend für etliche weitere Schulvergleiche. Sie sind bereitstehendes rhetorisches Stilmittel, das den Niveauverlust der universitären Bildung pointiert: Abgrenzungen, die nicht mehr gelten, werden zu Volkshochschulen, Berufsschulen, Gymnasien vorgenommen. Es sticht aber insbesondere die nach wie vor vehemente Grenzziehung zwischen Universitäten und Fachhochschulen hervor, mit der auf die bildungspolitisch 
geforderte Integration vermehrt praktisch-berufsvorbereitender Elemente in die universitären Curricula sowie die Umstellung auf die Bachelor- und Masterstudiengänge reagiert wird. Gerade letztere sollte schließlich auch zur Durchlässigkeit zwischen den beiden hochschulischen Ausbildungstypen beitragen.

Der grundsätzliche Charakter der „Bologna“-Kritik auch nach Umsetzung der Reform zeugt von einer weiterhin großen Skepsis, wenn nicht gar professoralen Frontstellung gegen sie. „Bologna“ versinnbildliche eine schädigende Ökonomisierung der Bildung, die mit markigen Worten zurückgewiesen wird. Wie sehr diese Ablehnung zuweilen in Untergangsrhetorik umschlägt, verdeutlichen die exemplarisch angeführten Stimmen. Das aufkommende „Employability“Paradigma, also die Ausrichtung des Studiums auf die Beschäftigungs- bzw. Arbeitsmarktfähigkeit der Studierenden, und die Humboldtsche Idee der Universität werden in den Beiträgen als konkurrierende Leitideen zum Sinn und Zweck akademischer Bildung stilisiert. Die von Kritikern wie Kamphausen eingeforderte „Freiheit von den Ansprüchen der Erwerbs- und Produktionsgesellschaft" (Kamphausen, F\&L 2/2013, S. 116) und der bildungspolitische Diskurs der 2000er Jahre, in dessen Zentrum explizit die Bedarfe der Wissensgesellschaft stehen, worauf unter Begriffen wie Responsivität und Responsibilität hingewiesen wird, sind letztlich kaum füreinander anschlussfähig. ${ }^{5}$

Indes darf nicht unerwähnt bleiben, dass sich ProfessorInnen in beiden Zeiträumen vereinzelt auch positiver zu „Bologna“ äußern. Während unter den sich öffentlich äußernden KritikerInnen eine auffällige geistes- und sozialwissenschaftliche Dominanz besteht, tritt der Ingenieurwissenschaftler Johann-Dietrich Wörner im Jahr 2000, zu diesem Zeitpunkt Präsident der TU Darmstadt und Vorsitzender des Akkreditierungsverbundes für Ingenieurstudiengänge, für die Einführung von eindeutig definier- und messbaren Qualitätsmaßstäben in der akademischen Ausbildung durch Akkreditierungsverfahren ein und spricht sich explizit für die Bachelor- und Masterstudiengänge und die Angleichung an internationale Standards aus. Denn der Diplom-Abschluss sei im Ausland zumeist „erklärungsbedürftig“ und erhalte nicht die „niveaumäßige Anerkennung“. Das „,neue System (ECTS, Modulstruktur)“ trage hingegen ,zur Transparenz, Erleichterung der Anerkennung und Anpassung an internationale Standards bei“:

„Durch Akkreditierung wird bestätigt, daß dem erworbenen Abschluß eine Ausbildung vorausgegangen ist, die definierte Kriterien und Standards einhält und

${ }^{5}$ Zur genaueren Begriffsbestimmung sowie dem hiermit umschriebenen Verhältnis von Wissenschaft zu Wissenschaftspolitik und Gesellschaft siehe etwa David Kaldewey (2015), Marc Torka (2015, S. 22-35) sowie Sabine Maasen und Sascha Dickel (2016). 
definierte Fähigkeiten, Fertigkeiten und Kenntnisse vermittelt, der Abschluß also keine ,Mogelpackung' darstellt.“ (Wörner, F\&L 10/2000, S. 510).

Letztlich sind es jedoch Stimmen wie die des Soziologen Kamphausen, die im öffentlichen Diskurs in kritischer Weise aufgegriffen werden und JournalistInnen wie zentralen politischen Reformprotagonisten gleichermaßen als Ausweis der Veränderungsresistenz des Professorenstandes dienen.

\subsection{Große Hoffnung „Bologna“: Erster Teil der journalistischen Perspektive zu Beginn der Reformen}

Der professorale argumentative Rückgriff auf Humboldt wird im betrachteten Spektrum des journalistischen Diskurses schnell als „Standesdünkel“ (Mohr, DER SPIEGEL 46/2000, S. 61) und Ausdruck eines Bewahrungswillens ausgelegt. „Nachlässige Professoren“ (Stoldt, DER SPIEGEL 43/1999,S. 76) und „Lordsiegelbewahrer“ (Spiewak, DIE ZEIT 14/2001) mit „altmodischen Bildungsidealen“ (Mohr, DER SPIEGEL 46/2000, S. 62) gehören ebenso zu den Zuschreibungen wie Sabine Etzolds prominent gewordene ironisierende Charakterisierung des DHV-Präsidenten Schiedermair als „Humboldts letzte[n] Krieger" in DIE ZEIT (14/2000). Die „Bologna“-Reformen stellen sich in der journalistischen Berichterstattung dann auch gänzlich anders dar als in F\&L. Während der professorale Protest von den journalistischen BeobachterInnen vor allem als eine unzeitgemäße Kritik dargestellt wird, werden die Reformvorhaben mehrheitlich begrüßt. Eine explizite Befürwortung der Reformen geht mit einer kritischen Perspektive auf ProfessorInnen einher. Diese Eindeutigkeit nimmt im Zeitverlauf zwar etwas ab, überwiegt aber weiterhin.

\section{„Employability“}

Den Ausgangspunkt vieler journalistischer Beiträge im betrachteten ersten Zeitraum bildete eine umfassende Defizitdiagnose des Status quo der universitären Lehre. Auf Seite der JournalistInnen überwog eine klare Zustimmung $\mathrm{zu}$ den Studienstrukturreformen und der mit ihnen verbundenen Zielsetzung, die Ausgestaltung und Inhalte des Studiums stärker an der „Employability“ der AbsolventInnen und den gewandelten Erfordernissen des Arbeitsmarkts auszurichten. Die avisierten Reformen wurden nicht nur befürwortet, sondern für überfällig erklärt.

Die „Sorbonne“- und bald darauffolgende „Bologna“-Erklärung in den Jahren 1998 und 1999 markierten eine Kehrtwende in der deutschen Hochschulpolitik 
und initiierten die Einleitung eines Reformprozesses, an dessen Ende - so die Hoffnung seiner Befürworter - ein umfassend modernisiertes Universitätsstudium stehen werde. Die klassische Idee der Universität und deren Verteidigung spielten in den journalistischen Beiträgen hingegen keine Rolle. Der mediale Diskurs betont vielmehr den „Beitrag der Universitäten zur gesamtgesellschaftlichen Wirtschaftsleistung“" (Liebeskind 2011, S. 11), den diese bislang vernachlässigt hätten. Die Deutung einer als Selbstzweck betriebenen Bildung erfährt damit insgesamt eine Delegitimierung.

Vor dem Hintergrund der im Jahr 2000 gerade verabschiedeten „Lissabon“Strategie zum europäischen Wirtschaftsraum sieht etwa ZEIT-Autor Kerstan - wir erinnern an das einleitend angeführte Zitat - im Hinblick auf die „Leistungsfähigkeit der deutschen Hochschulen“ einen entsprechenden Handlungsbedarf. Ein Hochschulstudium sollte sich aus seiner Sicht stärker an eine Berufsausbildung annähern. Die Zahl der HochschulabsolventInnen müsse „noch steigen“, der Weg zum Abschluss ,praxisnäher, kürzer und flexibler“ (Kerstan, DIE ZEIT 14/2000) werden. Damit schließt Kerstan an die angebotsorientierte Argumentation an, die die Arbeitsmarkt- und Beschäftigungspolitik im Sinne der „Agenda 2010“ zu diesem Zeitpunkt bestimmt. ${ }^{6}$ Die Universitäten seien dringend gefordert, sich stärker von ihrer Orientierung an der Ausbildung wissenschaftlichen Nachwuchses zu lösen und sich stattdessen ,um die Berufschancen ihrer Studenten und damit um die Weitergabe des Wissens in die Gesellschaft" zu kümmern. Demgegenüber, so Kerstan weiter, sei:

„,das deutsche Hochschulsystem [...] noch immer darauf ausgerichtet, Professoren hervorzubringen und nicht Abteilungsleiter. Und dort, wo es für Berufe qualifiziert, trägt es groteske Züge: Die Juristen werden zu Richtern ausgebildet, obwohl $80 \%$ von ihnen später als Anwalt arbeiten werden. Selbst die künftigen Ärzte und Lehrer, deren Beruf sich ganz um den Menschen dreht, studieren oft jahrelang, ohne einen Patienten oder Schüler zu Gesicht zu bekommen.“ (ebd.)

Kerstan moniert einen zu überwindenden Gegensatz zwischen einer wissenschaftlich ausgerichteten universitären Lehre und einer späteren Berufstätigkeit. Eine Praxisnähe von Studiengängen wird wie selbstverständlich als eindeutiger Vorzug begrüßt. Die als gegeben behauptete Praxisferne und die unzureichenden Bemühungen der Universitäten, ihre Studierenden und AbsolventInnen konkreter

${ }^{6}$ Für einen kurzen Überblick zur deutschen Arbeitsmarkt- und Beschäftigungspolitik seit der Wiedervereinigung siehe Michael Feil et al. (2008). 
an den Arbeitsmarkt heranzuführen oder auf diesen vorzubereiten, werden entsprechend kritisch gesehen. Folgerichtig wird die Autonomie von ProfessorInnen bei der Gestaltung ihrer täglichen Lehre und Forschung keineswegs als besonders schützenswertes Gut eingestuft, sondern vielmehr als Hindernis bei der Erreichung der Reformziele gedeutet:

„Viele Hochschullehrer und Politiker haben die Notwendigkeit für eine grundlegende Reform inzwischen erkannt. An den Hochschulen ist Bewegung zu spüren. Aber die Kräfte der Beharrung sind stark. Die grundgesetzlich verbriefte Freiheit der Forschung und Lehre verstehen viele Professoren als Schutzschild gegen jeden Ruf nach Erneuerung. Die Reformer an den Universitäten verdienen alle Unterstützung, damit nicht auch der Appell aus Lissabon ungehört verhallt.“ (ebd.)

In seinem Beitrag deutet er somit noch eine Problematik anderer Art an, die vor dem Hintergrund der parallel diskutierten Pläne zur Reformierung des Dienstrechts und zur Stärkung des Wettbewerbs Gegenstand weiterer Kontroversen darstellte: die Autonomie der ProfessorInnen in ihrer Amtsführung, hier vom Autor provokant als „Schutzschild gegen jeden Ruf nach Erneuerung“ problematisiert. Wir werden auf diesen Punkt später zurückkommen, vorerst aber bei der universitären Lehre verweilen.

Konkreter als bei Kerstan wird das Problem der fehlenden Praxisnähe in anderen Beiträgen anhand von einzelnen Disziplinen wie den Politikwissenschaften, Naturwissenschaften wie Chemie und Biologie oder ingenieurwissenschaftlichen Fächern wie der Elektro- und Informationstechnik - letztere insbesondere vor dem Hintergrund der „New Economy“ und des gerade beginnenden Internetzeitalters in den späten 1990er Jahren - dargestellt. Wieder geht es um „praxisferne, wissenschaftsinterne Sachdebatten“, das Pflegen von „Großordinarien-Attitüden“ und ,[B]erieseln [der] Studierende[n] mit Unwesentlichem“ (Koch et al., DER SPIEGEL 13/2000, S. 44) ${ }^{7}$ anstelle einer überfälligen Ausrichtung der Lehre auf aussichtsreiche und zukunftsweisende Berufsfelder etwa Politikberatung oder Start-ups in der Biotechnologie oder der IT-Branche. Als Experten kommen neben Wirtschaftsvertretern teilweise auch Professoren zu Wort, die für eine viel engere Verbindung von Wissenschaft und Unternehmertum plädieren. So äußert sich etwa Erich Staudt, Arbeitsökonom und Innovationsforscher an der Universität Bochum, in einem Interview mit Martin Spiewak in

\footnotetext{
${ }^{7}$ Julia Koch, Joachim Mohr, Mathias Müller von Blumencron, Padma Rao, Michael Sauga, Michael Schmidt-Klingenberg, Hilmar Schmundt, Hajo Schumacher.
} 
DIE ZEIT zu der Situation erwerbsloser BiologInnen und ChemikerInnen, die er, was den Titel des Artikels abgibt, als ,[ü]berforderte Fachidioten“ einstuft:

\begin{abstract}
„Das Problem ist: Sie haben das Falsche gelernt. Sie sind hoch qualifiziert, aber inkompetent. Denn die Ausbildung an den Hochschulen ist immer noch auf den klassischen Forscher ausgerichtet, der entweder an der Universität bleibt oder in einem Labor der Großindustrie arbeitet. Doch biotechnologische Unternehmen suchen nach der Gründung nicht nur brillante Forscher. Sie brauchen zur Expansion vor allem Leute, die neben ihren Fachkenntnissen in der Produktion zu Hause sind, die in der Lage sind, Kunden für die Produkte zu finden und sie zu beraten. Das überfordert den typischen Fachidioten, den wir in Deutschland ausbilden." (zitiert in: Spiewak, DIE ZEIT 46/1999).
\end{abstract}

In etwas abgeschwächter Weise stellt der Journalist Wigbert Löer in DIE ZEIT den fehlenden Praxisbezug der Politikwissenschaften dar:

„Für halbstündige Exposés auf Fachchinesisch fehlt den Politikern die Zeit. Was mancher Professor weiterhin genüsslich ignoriert. Er pocht bei seinen Studenten akribisch auf vermeintlich wissenschaftlichen Stil. Deutungsfreude und zugespitzte Thesen, gar noch mit flotter Feder geschrieben, sind in Haus- und Abschlussarbeiten oft verpönt. Ein Konvolut von Fußnoten und schachtelig-schwerverständliche Sätze sind weniger risikoreich: In solch einem Slang schreibt der Professor oft auch freilich ohne in der politischen Klasse Gehör zu finden. Die Generalsekretäre der Parteien sind auf deutlich formulierte Meinungen und klar verständliche Urteile von Experten erpicht; Erbsen zählen können sie selber.“ (Löer, DIE ZEIT 22/2000)

Löer kritisiert nicht in erster Linie die Studieninhalte, sondern eine wissenschaftliche Sozialisation, die zu einer ,abgehobenen“ Darstellung von Ergebnissen führe, welche für ein Publikum außerhalb des universitären Kontextes kaum zugänglich sei. Damit räumt er im Gegenzug den Anforderungen des politischen Systems größeres Gewicht ein als den Spezifika wissenschaftlichen Arbeitens und Argumentierens. Was sich bei Löer andeutet, setzt sich in weiteren Artikeln teils sehr explizit fort: Negativzuschreibungen in Richtung ProfessorInnen, um die Reformbedürftigkeit deutscher Universitäten zu unterstreichen.

Als Kronzeugen des Reformbedarfs werden auch Studierende bzw. AbsolventInnen angeführt. Im eigens initiierten SPIEGEL-Ranking wird dem Urteil der Zielgruppe des Studienangebots große Bedeutung beigemessen: nicht nur hinsichtlich allgemeinerer und struktureller Rahmenbedingungen, sondern auch mit Blick auf das Verhältnis zu den ProfessorInnen und deren Engagement in der persönlichen Betreuung und Lehre. Das Bedürfnis der Studierenden nach intensiver Betreuung, aber auch ihre pragmatische Aneignung des Studiums als möglichst zielführende Etappe auf dem Weg zu besseren Chancen 
auf dem Arbeitsmarkt werden als Bewertungsmaßstäbe übernommen, diesbezüglich konstatierte Missstände zum Ausgangspunkt der Kritik an den Leistungen der Universitäten und speziell der ProfessorInnen gemacht. Die defizitäre oder gar fehlende Betreuung der Studierenden an den Universitäten rückt dabei kritisch in den Blick, während den Fachhochschulen eine Vorbildrolle zugesprochen wird. Dort gebe es eine adäquate Betreuung der Studierenden, während anonyme Massenveranstaltungen das Bild an den Universitäten prägten. Diese Schieflage wird zwar durchaus auch der Unterfinanzierung der Universitäten und einem entsprechend schlechten zahlenmäßigen Betreuungsverhältnis in vielen Fächern zugerechnet. Doch die Mitverantwortung einer überheblichen, an Lehrqualität und Betreuungsaufgaben desinteressierten Professorenschaft für die konstatierten Missstände spielt in der journalistischen Darstellung eine gleichermaßen wichtige Rolle.

\title{
Desinteresse an Lehre
}

Hohe Studienabbrecherquoten und ,überlange Studienzeiten“ an deutschen Universitäten, zu diesem Zeitpunkt zentrale Problemfelder, seien daher auch weder allein auf „,mangelhafte Rahmenbedingungen“ noch auf die ,,angebliche Faulheit der Studierenden" zurückzuführen, so die SPIEGEL-Autoren Markus Feldenkirchen und Joachim Mohr (DER SPIEGEL 12/2001, S. 62):

\begin{abstract}
„An manchen Großstadt-Unis im Westen scheinen noch Relikte aus der Zeit der Bildungsexpansion in den siebziger und achtziger Jahren weiter zu wirken. Damals herrschte eine Allianz des Stillschweigens zwischen Studenten, Professoren und Politikern: Die Studierenden verlangten, sich in Ruhe und frei jeglichen Leistungsdrucks bilden zu können, die Professoren hatten keine Lust, sich neben ihrer Forschung um Studienpläne und Regelstudienzeiten zu kümmern, und die Wissenschaftsminister wollten weder mit den Studenten noch mit den Professoren Ärger - mochten die Studienzeiten auch stetig steigen.“
\end{abstract}

Das Verdachtsmoment einer generellen Vernachlässigung der Lehre an den Universitäten wird wiederholte Male aufgegriffen. Im Kontext der Diskussion der Ergebnisse des SPIEGEL-Ranking (DER SPIEGEL 15/1999) gelangen Jürgen Dahlkamp und seine KollegInnen ${ }^{8}$ (DER SPIEGEL 15/1999, S. 64) zu einem ähnlichen Urteil:

\footnotetext{
${ }^{8}$ Jürgen Dahlkamp, Florian Gless, Almut Hielscher, Joachim Mohr, Bettina Musall, Irina Repke, Andrea Stuppe und Hans-Jörg Vehlewald.
} 
„Während angelsächsische Universitäten schon immer auf eine intensive Betreuung jedes einzelnen Studenten großen Wert gelegt haben, galt in Deutschland von jeher das Ideal des Einzelkämpfers. Wissen und Methodik mußten im Alleingang erarbeitet werden, sei es in der Vorlesung, sei es im Seminar. Bis in die frühen sechziger Jahre hinein war dieses Modell deswegen so erfolgreich, weil die Zahl der Studenten gering und jeder Hochschullehrer im Bedarfsfall ansprechbar war. In den westdeutschen Massenuniversitäten der achtziger und neunziger Jahre dagegen findet mancher Student womöglich erst im fünften Semester einen ersten Kontakt zu einem Professor. Aus Sicht der Dozenten haben viele ihrer Studenten allerdings an einer Universität gar nichts verloren: Jedem, der eher betreutes Lernen wünsche, stehe der Weg in eine Fachhochschule frei.“

Der Vergleich mit den Fachhochschulen spielt insgesamt keine unwichtige Rolle, deren hier angedeutete professorale Geringschätzung von den JournalistInnen keineswegs geteilt wird. Dahlkamp (DER SPIEGEL 15/1999, S. 98) differenziert an anderer Stelle zwischen „FH-Lust“ und „Uni-Frust“ und lobt das neue Selbstbewusstsein der Fachhochschulen, die „,beflügelt vom Wunsch der Wirtschaft nach Absolventen [seien], die im ersten halben Jahr nicht unter Praxisschock leiden - und Geld bringen, anstatt welches zu kosten“. Den „Uni-Frust“ führt der Autor wiederum explizit auf die allgegenwärtigen habituellen Eigenheiten der UniversitätsprofessorInnen zurück, was er am Beispiel der Erfahrungen eines ehemaligen Universitätsstudenten verdeutlicht, der sein „wahres Studienglück“ erst nach Wechsel an eine Fachhochschule fand. Dort stellte dieser „nicht nur“ fest, dass ProfessorInnen ihren Studierenden „gerade in die Augen schauten, sondern sogar beim Arbeiten über die Schulter". An der Universität sei hingegen ein anderer Professorentypus anzutreffen, wie der Journalist weiter ausführt:

„Sein Blick ging demonstrativ nach oben. Wie üblich, wenn der Herr Professor an der Universität Freiburg dozierte, versagte er den Studenten der Forstwirtschaft die Gnade seiner Aufmerksamkeit und starrte beim Extemporieren an die Decke, als wollte er sich beim lieben Gott darüber beklagen, daß ihm diese jungen Kretins schon wieder die Muße für die wahren Wonnen der Wissenschaft raubten." (Dahlkamp, DER SPIEGEL 15/1999, S. 98).

Zur Illustration greift auch Spiewak in DIE ZEIT das rückblickende Urteil einer Studentin auf, die aufgrund ihrer universitären Erfahrungen an eine Fachhochschule wechselte:

„400 Studenten drängten sich im Vorlesungssaal und mussten zuhören, ,wie vorne einer ein Buch vorlas‘. Stellte der Professor einmal eine Frage, hieß es: ,Die Dame 
da oben, neben dem Herrn im roten Pullover, was sagen Sie dazu?`Auf einen

Termin beim Professor wartete man wochenlang. " (Spiewak, DIE ZEIT 08/2000). ${ }^{9}$

DER SPIEGEL und DIE ZEIT zeichnen in diesem Punkt ein recht übereinstimmendes Bild: Während den Universitäten ein „Hang zu verzopften Traditionen und altmodischen Bildungsidealen" zugeschrieben wird, mit dem sie die aktuelle Entwicklung zur Wissensgesellschaft „verschlafen“ (Mohr, DER SPIEGEL 46/2000, S. 62), also den Anschluss verpassen, verdienten Fachhochschulen, so der Tenor, eine hochschulpolitische Aufwertung, da sie praxisnah ausbildeten und sich mit neuen Studiengängen an der späteren Beschäftigungsfähigkeit ihrer AbsolventInnen orientierten. Dass sie mit diesem Weg richtig lägen, wird durch Aussagen von Studierenden bzw. AbsolventInnen dieser Studiengänge zusätzlich untermauert. So fasst Spiewak (DIE ZEIT 15/1999) das positive Echo von WirtschaftsjuristInnen wie folgt zusammen:

„Die ersten Wirtschaftsjuristen aus Lüneburg und Mainz haben alle einen Arbeitsplatz gefunden. Das Interesse der Studenten am neuen Fach ist gewaltig. Fast überall übertrifft die Zahl der Bewerber die Studienplätze um ein Vielfaches. Nur wer einen Notendurchschnitt von unter 2,0 vorweisen kann, hat an den meisten Fachhochschulen eine Chance."

In der Äußerung klingt an, was Spiewak auch in einem späteren Beitrag wieder aufgreift: dass das Niveau der Studierenden, die an die Fachhochschulen kommen, hoch ist und die klassische Hierarchisierung zwischen Universitäten und Fachhochschulen auch dahin gehend nicht länger zutreffend sei. ${ }^{10}$ Die ,,alten

${ }^{9}$ Dass aus Studierenden- bzw. Absolventensicht vor allem kleine Hochschulen - „solide Provinzuniversitäten“, wie der Autor Stefan Klein (DER SPIEGEL 15/1999: 87) anmerkt - und private Hoch- sowie Fachhochschulen als Gewinner der beiden SPIEGEL-Rankings hervorgehen, wird auch einem Professorentypus zugeschrieben, der für die Studierendenzufriedenheit maßgeblich, an den meisten Universitäten allerdings nur selten anzutreffenden sei: „Bayreuth (8000 Studenten), Konstanz (7000) und Siegen (11 000) [...] belegten stets Spitzenplätze. An diesen kleineren Universitäten, so urteilen die Studenten, stimmen die Bedingungen für ein erfolgreiches Studium; vor allem kümmert sich die Professorenschaft nicht nur um karrierefördernde Forschungsprojekte, sondern auch um ihre Studenten.“ (Dahlkamp et al., DER SPIEGEL 15/1999: 62).

${ }^{10}$ In diesem Zusammenhang wird auch das Promotionsmonopol als fragwürdiges Privileg der Universitäten thematisiert. So zitiert etwa Dahlkamp den damaligen Rektor der HS Esslingen, Jürgen van der List, der die Verwehrung der Promotion für FachhochschulAbsolventen als „Schikane“ und „Verteidigung des Heiligen Gral“ seitens der Universitäten einstuft. Auch aus Sicht der zu diesem Zeitpunkt amtierenden Bundesbildungsministerin 
Qualitätsmaßstäbe“ hätten sich vielmehr ,umgedreht“: Während die Studierenden an den Fachhochschulen mittlerweile häufig „Einser-Abiturienten“ seien, bliebe den ,schlechten Abiturienten [...] nur der Weg zur Universität.“ (Spiewak, DIE ZEIT 8/2000).

In weiteren Beiträgen wird explizit die professorale Sorgfaltspflicht kritisch in den Blick genommen. Aus einer Parteinahme für die Interessen der Studierenden, aber auch aus einer allgemeineren Befürwortung der universitären Modernisierung heraus wird die professorale Verteidigung der eigenen Autonomie zu einem unzeitgemäßen Privileg erklärt. Da ProfessorInnen im Dienst einer ,größeren“ Sache wie der „Employability“ ihrer Studierenden und der Verkürzung der Studienzeiten agieren sollten, hätten sie sich auch dann anzupassen, wenn die neuen Anforderungen ihrem Selbstverständnis und Bildungsideal widersprechen:

„Die Manager-Elite für den globalen Wettbewerb - an den meisten deutschen Hoch-
schulen wird sie nicht ausgebildet. ,Insbesondere an den Universitäten ist die Ver-
bindung zur Arbeitswelt oft zu gering', gibt Klaus Landfried zu. Der Präsident
der Hochschulrektorenkonferenz kritisiert indirekt den Standesdünkel mancher
Dozenten: ,Praxisbezug hat nichts mit Niveauverlust zu tun.“ Auch Allianz-
Personalchef Schneevoigt bemängelt, viele Wissenschaftler hätten zu wenig
Interesse an der Wirklichkeit in den Betrieben: Vor ein paar Jahren habe er einigen
angehenden Professoren angeboten, sie könnten zeitlich befristet eine Aufgabe im
Konzern übernehmen, um so die Arbeit bei einem großen Versicherer kennen zu
lernen. ,Keiner hatte sich gemeldet." (Mohr, DER SPIEGEL 46/2000, S. 61/62)

ProfessorInnen werden somit keineswegs als Opfer der Verhältnisse, sondern umgekehrt als fragwürdige NutznießerInnen eingestuft. Noch deutlicher wird dies in jenen Beiträgen, in denen eine grundsätzlichere Vernachlässigung der Lehre thematisiert wird. Dies schließt auch eine ,zu freie“ Auslegung der Amtspflichten ein. Insbesondere der SPIEGEL veröffentlicht in diesem Zeitraum vermehrt Beiträge, die sich skandalträchtigen Einzelfällen von willkürlicher Amtsausübung bis hin zu Amtsmissbrauch widmen.

Die Beiträge gehen von konkreten Fällen bzw. Vorwürfen der Pflichtverletzung bei der Aufgabenerfüllung im Bereich der Lehre aus. Nicht allein der ,faule' Hochschullehrer steht hier zur Rede, sondern ein Professorentypus, der seine Autonomie und Machtposition in massiver Weise zu eigenen Gunsten aus-

Edelgard Bulmahn seien die bis dato 30 vergebenen Doktortitel an FH-AbsolventInnen „,eine lächerlich geringe Zahl“. 
nutzt. ${ }^{11}$ Die Vorwürfe gehen deutlich über das Bild des ,DiMiDo'-Professors hinaus, indem eine fehlende Verlässlichkeit der Prüfungsverfahren wie kurzfristige Veränderungen der Termine und Inhalte bis hin zur Fälschung von Protokollen faktisch nicht durchgeführter Prüfungen moniert werden. Angriffslustig spricht die SPIEGEL-Autorin Katharina Stegelmann dann auch vom „Störfaktor Student", den es aus professoraler Sicht auszuschalten gelte, um sich „Forschung, Karibik oder Karriere“ zu widmen:

„Im Wissenschaftsbetrieb hat die Forschung einen höheren Stellenwert als die Lehre. Kein Wunder, daß manche Professoren den Umgang mit den Studenten auf das Notwendigste beschränken. Diverse Forschungsaktivitäten und Nebentätigkeiten schlagen sich aber auch schlicht auf dem Konto nieder. Die im Grundgesetz verbriefte Freiheit der Forschung und das geltende Recht auf Nebentätigkeit eröffnen ungeahnte Möglichkeiten: florierende Büros von Architektur-Hochschullehrern, lukrative Beraterverträge mit Verbänden und Konzernen, hochdotierte Gutachten von Chemie-Professoren. Ob Forschung, Karibik, Karriere - alles braucht seine Zeit. Daher gilt es, den Störfaktor Student weitgehend auszuschalten.“ (Stegelmann, DER SPIEGEL 24/1999, S. 60).

Stegelmann nennt Beispiele für , pflichtvergessene ' ProfessorInnen und beschreibt konkrete „Technik[en]“, die HochschullehrerInnen nutzten, um möglichst geringe Teilnehmerzahlen in ihren Veranstaltungen zu erreichen:

„Die beste Voraussetzung, die Beziehung zu den Studierenden einzuschränken, ist ein Ruf, der von großer Strenge und hohen Ansprüchen kündet. Für ein germanistisches Seminar an der Uni Hamburg zum Beispiel lockte nicht gerade die Zugangsvoraussetzung, in der vorlesungsfreien Zeit drei 500-Seiten-Romane zu lesen, sie zusammenzufassen und Referatsvorschläge auszuarbeiten. Der Hinweis ,Nur mit Voranmeldung ' fehlte nicht, die Teilnehmerliste war im Dickicht des Schwarzen Bretts verborgen, die Anmeldefrist denkbar knapp gehalten.“ (ebd.)

Bei den avisierten Veränderungen geht es daher auch um eine stärkere Kontrolle der professoralen Lehrpflichten. Denn obwohl ,die überwiegende Mehrheit der deutschen Professoren brav ihren Lehrverpflichtungen“ nachkäme, fänden „,unerklärliche Abwesenheiten und listige Abwehrstrategien gegen lästige Studenten [...] sich an vielen Universitäten.“ (ebd., S. 56).

\footnotetext{
${ }^{11}$ Als Beispiel dient etwa der volkswirtschaftliche Fachbereich der Hamburger Universität, an dem einzelne Hochschullehrer nicht nur zu selten in ihren Seminaren erschienen seien, sondern ebenso bei Examensprüfungen auf jegliche Sorgfaltspflicht gegenüber den KandidatInnen verzichtet haben sollen (Stoldt, DER SPIEGEL 43/1999: 76).
} 
Für den SPIEGEL-Journalisten Hans-Ulrich Stoldt (DER SPIEGEL 43/1999, S. 76) sprechen die geschilderten Probleme für die geplante Dienstrechtsreform:

\begin{abstract}
„Die Anschuldigungen untermauern die Forderungen nach einer besseren Leistungskontrolle von Professoren und einer Reform des Dienstrechts, die immer stärker die Diskussion um die Modernisierung der deutschen Universitäten beherrschen. ,Der Professorenstand ist eine der Zünfte, die aus grauer Vorzeit stammen', sagt Klaus Landfried, Präsident der Hochschulrektorenkonferenz. Noch immer können die Lehrherren recht feudal herrschen.“
\end{abstract}

Der „Professorenstand“ wird als Problem gerahmt. Er steht nicht nur für eine gewisse Antiquiertheit, sondern auch für ein quasi feudales Verständnis der Amtsausübung und eigenen Rolle, bei der die Einhaltung von Dienstpflichten hinter Machtansprüchen und Eigeninteressen zurücktreten kann. Insofern entsteht der Eindruck, dass die Berufsgruppe der ProfessorInnen einer stärkeren - externen Kontrolle bedarf, um die offensichtlichen Tücken der zugestandenen Autonomie in den Griff zu bekommen.

\title{
2.3 Schluss mit der Professorenselbstherrlichkeit: Zweiter Teil der journalistischen Perspektive zu Beginn der Reformen
}

Unter dem an einen Slogan der Studentenbewegung der 1960er Jahre erinnernden Titel „Den Muff aus den Talaren“ schreibt Wolfgang Hoffmann in DIE ZEIT (36/1999):

„Die Nachricht hört man gern: Bildungsministerin Edelgard Bulmahn will den Professoren ein neues Besoldungsrecht verordnen. Beifall freilich ist erst angebracht, wenn die Hochschullehrer am Ende wirklich nur das bekommen, was sie auch verdienen."

Weiter heißt es:

„Solange manche Uni-Lehrer Forschung und Lehre nur als individuelle Freiheit missbrauchen, ohne dass sie Sanktionen zu fürchten hätten, werden die deutschen Hochschulen aus ihrem Tief nicht herauskommen. Das schadet der Volkswirtschaft und bringt den Standort Deutschland ins Hintertreffen. Die Kombination aus Beamtenrecht und Freiheit der Wissenschaft ist eine Art Schlaraffenland, in dem es sich bequem leben lässt.“" (ebd.) 


\title{
W-Besoldung
}

In denjenigen Artikeln, die explizit die Dienstrechtsreform, also die Einführung der leistungsbezogenen W-Besoldung sowie der Juniorprofessur, zum Thema haben, setzt sich die kritische Perspektive auf ProfessorInnen fort und verbindet sich mit Negativbildern professoraler Aufgabenerfüllung. Faulheit, eine Missachtung der Dienstpflichten und fehlende wissenschaftliche Leistungen gehören zu den Zuschreibungen, sodass die Einführung einer leistungsbezogenen Besoldung als entsprechender Schritt in die richtige Richtung gewertet wird. Zudem wird eine stärker an der individuellen Leistung orientierte Bezahlung als Förderung von Wettbewerb in der Forschung, der sich in der Einwerbung von Drittmitteln und in Publikationen zeigt, begrüßt. Eine gute Professorin wird nicht nur über die Verlässlichkeit in Lehre und Betreuung des Nachwuchses definiert, sondern ebenso über die individuellen Leistungen in der Forschung und den Beitrag zum Erkenntnisfortschritt innerhalb der jeweiligen Disziplin. Neben die Dichotomie von ,faul' und 'fleißig' tritt entsprechend die Einteilung in ,internationale Koryphäe“" und ,,akademische Tiefflieger": ${ }^{12}$

\begin{abstract}
„Derzeit gilt an deutschen Universitäten und Fachhochschulen noch die gegenteilige Maxime - dienstlich unauffällig altern und dabei zuverlässig immer mehr verdienen. In 15 Stufen steigt das professorale Salär alle zwei Jahre; dabei spielt es keine Rolle, ob ein Dozent in der Wissenschaft eine internationale Koryphäe ist oder als akademischer Tiefflieger betrachtet wird, ob er 100 Studenten pro Jahr oder keinen einzigen erfolgreich durchs Examen bringt. Mit dem Muff unter den Professoren soll es vorbei sein, geht es nach dem Willen der Bildungsministerin." (Koch/Mohr, DER SPIEGEL 16/2000, S. 34)
\end{abstract}

Insofern geraten auch solche ProfessorInnen in den skeptischen Blick, die „unauffällig altern“ - ProfessorInnen also, die sich nichts zu Schulden kommen lassen, aber auch nicht durch besondere Leistungen auffallen und dahin gehend eher dem klassischen Stereotyp des Beamten entsprechen. Die Verhältnisse an deutschen Universitäten werden auch hier als „Muff“ charakterisiert, den es im Zeichen größerer Wettbewerbs- und Leistungsorientierung dringend zu überwinden gelte. Als positiv konnotierter Vergleichsmaßstab dienen die USA, wo sich ProfessorInnen dem jährlichen „Rapport“ (Mohr, DER SPIEGEL 36/1999,

\footnotetext{
${ }^{12}$ Dass die gleichzeitige Erfüllung beider Anforderungen - sowohl engagierte Lehre als auch außerordentliche Leistungen in der Forschung - angesichts der Bedingungen von Massenuniversitäten keineswegs leicht zu erbringen ist und in der Praxis in Handlungsdilemmata münden kann, findet hier keine Erwähnung.
} 
S. 114) stellen müssten. Interessant ist in diesem Kontext auch, wie Gegenstimmen bzw. der professorale Widerstand gegen die geplanten Reformen kommentiert werden. Indem der DHV als einziger Gegenspieler genannt und als „Kartell der professoralen Besitzstandswahrer“ (Koch/Mohr, DER SPIEGEL 16/2000, S. 34) charakterisiert wird, kann dessen Kritik, dies legt die Formulierung nahe, nur als Ausdruck interessenpolitischer Motive verstanden werden:

\begin{abstract}
„Mit Abscheu und Empörung hingegen reagierte, wie erwartet, der Deutsche Hochschulverband auf die Revolution an den Hochschulen, die Bulmahn anzetteln will. Das Kartell der professoralen Besitzstandswahrer lehnt so viele Neuerungen kategorisch ab: ,Das Grundgehalt um 1500 Mark abzusenken ist skandalös`, wettert Präsident Hartmut Schiedermair.“ (ebd.)
\end{abstract}

Dass die Haltung des DHV als erwartungsgemäß eingestuft wird, heißt hier, sich nicht weiter mit den Argumenten befassen zu müssen. Demgegenüber erhält Bundesbildungsministerin Bulmahn mehr Schützenhilfe, denn es wird von ,,zahlreiche[n] Experten" gesprochen, die die geplanten Reformen hinsichtlich ihrer Reichweite noch für unzureichend hielten und dafür plädierten, den Beamtenstatus von ProfessorInnen abzuschaffen. Im Sinne einer weiteren ,Stimme der Vernunft" wird in DIE ZEIT der an Bulmahn adressierte Brief von 460 deutschen im Ausland tätigen WissenschaftlerInnen herangezogen, in dem diese nicht nur die Reformen befürworten, sondern auch den Widerstand der deutschen ProfessorInnen mit einer rein strategischen Interessenverteidigung gleichsetzen. Spiewak folgt weitgehend ihrer Perspektive:

„Nun aber - auch das ist neu - mischen sich Uni-Flüchtlinge in die Debatte ein. Sie halten den Lordsiegelbewahrern des Weiter-so-aber-mit-mehr-Geld vor: Nicht die Reform, sondern der Status quo schwäche die deutschen Universitäten im Kampf um die besten Köpfe. Das schreiben 460 deutsche Wissenschaftler im Ausland in einem offenen Brief an Ministerin Bulmahn und ermuntern sie, standhaft zu bleiben. Für talentierte ausländische Nachwuchswissenschaftler sei Deutschland ,allenfalls zweite Wahl', die hiesige Forschungslandschaft zu ,hierarchisch und unflexibel'." (Spiewak, DIE ZEIT 14/2001)

Und an anderer Stelle heißt es weiter:

„In ihrem Brief bezeichnen die deutschen Forscher im Ausland, unter ihnen zwei Nobelpreisträger, solchen Widerstand gegen die Hochschulreform als Interessenpolitik einer Gruppe, die ,um ihre Macht und Privilegien fürchtet ${ }^{t}$. Dabei sei die akademische Struktur des deutschen Hochschulsystems schon längst nicht mehr 
zeitgemäß, weil unangemessen hierarchisch und unflexibel.“ (Spiewak, DIE ZEIT 14.3.2001)

Mit dem Protest der deutschen WissenschaftlerInnen und dem Brief der „Uni-Flüchtlinge“ stehen sich keine zwei ebenbürtigen Meinungen gegenüber, die es abzuwägen gelte. Vielmehr bekommen die im Ausland tätigen WissenschaftlerInnen - noch verstärkt durch den Hinweis auf zwei Nobelpreisträger unter ihnen - die Deutungsmacht zugeschrieben. Sie durchschauen, folgt man Spiewak, nicht nur die niederen Motive des hiesigen professoralen Protestes, sondern stehen auch dafür, durch das deutsche universitäre System quasi zum Weggang gezwungen worden zu sein, um im Ausland auf bessere - „zeitgemäß[e]“ - Bedingungen für ihre akademische Karriere und wissenschaftliche Tätigkeit zu treffen. Den deutschen ProfessorInnen bleibt wiederum nicht mehr als der fragwürdige Status von „Lordsiegelbewahrern“, die ihre eigenen Privilegien verteidigen, anstatt für die Zukunft der Universitäten und NachwuchswissenschaftlerInnen Verantwortung zu übernehmen.

\title{
Juniorprofessuren
}

Die zu diesem Zeitpunkt geplante Ersetzung der Habilitation durch die Einführung von Juniorprofessuren wird journalistisch ebenso zustimmend begleitet. Die USA bzw. die dortigen Bedingungen an den Universitäten spielen auch hier wieder eine prominente Rolle. Während der wissenschaftliche Nachwuchs an den amerikanischen Universitäten über die angemessene Freiheit verfüge, um ,eigene Projekte voranzutreiben, statt Kopier- und Vorlesungsaufträge zu erledigen“ (Neubacher, DER SPIEGEL 4/2001, S. 144), verlange der Weg zur Professur in Deutschland hingegen eine ,gebückte Haltung“ (Stegelmann, DER SPIEGEL 33/2001, S. 50):

\begin{abstract}
„Ausgebeutet wie ein Leibeigener, dient der wissenschaftliche Assistent Jahr um Jahr seinem Professor. Der Nachwuchsforscher ist schon ergraut, wenn sein Chef gnädig die Habilitationsschrift akzeptiert und damit die Aufnahme in die erlauchte Runde der Hochschullehrer gewährt. Die Horrorvision ist noch immer weit verbreitet, aber selbstbewusste Jungakademiker wollen diese Rolle nicht mehr übernehmen. ,Jetzt noch mal sechs Jahre untergeordnet arbeiten? Nein. ' Der promovierte Philosoph Sebastian Luft, 31, will ,die Ochsentour der Habilitation“ nicht mitmachen." (ebd.)
\end{abstract}

Der Habitus der ProfessorInnen wird über die Ausnutzung der eigenen Machtposition innerhalb der universitären Hierarchie beschrieben. Hinsichtlich ihrer Beziehung zum wissenschaftlichen Nachwuchs sind insofern nicht Kooperation 
oder Unterstützung thematisch, sondern die Aufrechterhaltung einer subalternen Position und eines persönlichen Abhängigkeitsverhältnisses, innerhalb dessen sich die ,ergraute[n] Nachwuchswissenschaftler“ anzupassen haben und dennoch bis zuletzt kaum sicher sein können, für ihre Mühen anerkannt zu werden. So argumentiert Etzold mit Blick auf die Juniorprofessuren in DIE ZEIT:

\begin{abstract}
„Diese an deutschen Hochschulen bislang unbekannte Personalkategorie soll - nach dem Vorbild des bewährten amerikanischen assistant professor - dem wissenschaftlichen Nachwuchs mehr Selbstständigkeit für eigene Forschung und Lehre eröffnen. So bindet sie ihn zum Beispiel nicht mehr an einen Lehrstuhl und damit an dessen Inhaber. Juniorprofessoren können sich an den Hochschulen bewerben und dort bewähren. Das erhöht ihre eigenen Karrierechancen und kurbelt den Wettbewerb unter den Universitäten an, die sich künftig um den qualifiziertesten Nachwuchs raufen werden. Das ist zumindest die Hoffnung.“ (Etzold, DIE ZEIT 40/2001)
\end{abstract}

Die Vergrößerung der Autonomie des wissenschaftlichen Nachwuchses im Rahmen von Juniorprofessuren wird also in doppelter Weise befürwortet: als Mittel zum Abbau ohnehin überkommener Hierarchien und zur Förderung einer leistungsorientierten verjüngten Elite für den internationalen Wettbewerb.

\title{
Leitungen als Hoffnungsträger
}

Interessant in diesem Kontext ist schließlich noch, wie im Gegenzug zum reformresistenten „Professorenstand“ die Hoffnungsträger an deutschen Universitäten dargestellt werden, die sich für die aktive Durchsetzung von Reformen, die Überwindung professoraler Privilegien und mehr Wettbewerbsorientierung engagieren. Dafür stehen vor allem einige Universitätsrektoren bzw. -präsidentinnen. Ihnen ist nicht zuletzt gemeinsam, Neuerungen auch gegen habitualisierte Vorbehalte aufseiten der ProfessorInnen und zulasten der eigenen Beliebtheit durchzusetzen. Darüber hinaus spielt ihr bisheriger wissenschaftlicher Werdegang eine wichtige Rolle, indem betont wird, dass es sich um bis dato erfolgreiche Wissenschaftler handele, die sich nicht aus Mangel an besseren beruflichen Alternativen für die Belange der Hochschulen einsetzten. Mit Blick auf Wolfgang Herrmann, den 1995 ins Amt gekommenen Präsidenten der TU München, heißt es beispielsweise in DIE ZEIT:

„Dabei entspringen Herrmanns Vorwürfe und Forderungen nicht klugen Kommissionspapieren, sondern akademischer Praxis. Niemand kann ihm vorwerfen, er betreibe Hochschulpolitik, weil er es als Wissenschaftler nicht weit gebracht hat. Mit 25 Jahren wurde er promoviert, fünf Jahre später kam die Habilschrift, mit 34 Jahren war er Professor. Seine Forschungen haben ihm Gastprofessuren in Frankreich, Japan, den USA und den Niederlanden eingebracht - sowie nahezu alle Aus- 
zeichnungen, die man als Chemiker in Deutschland erhalten kann, inklusive des angesehenen Leibniz-Preises der Deutschen Forschungsgemeinschaft. Wer nach so einer Forscherkarriere ein Universitätsamt übernimmt, muss schon besondere Gründe haben. Schlechte Erfahrungen zum Beispiel.“ (Spiewak, DIE ZEIT 29/1999)

In nahezu gleichem Wortlaut beschreibt Spiewak zwei Jahre später den Präsidenten der Berliner Humboldt Universität, Jürgen Mlynek:

\begin{abstract}
„Dabei entspringen Mlyneks Vorstellungen nicht klugen Kommissionspapieren, sondern seiner akademischen Praxis. Niemand kann dem Physiker vorwerfen, er betreibe Hochschulpolitik, weil er es als Wissenschaftler nicht weit gebracht habe. [...] Er hat viel publiziert, unter anderem in Nature und Science, neun Patente angemeldet und nahezu alle Auszeichnungen eingestrichen, die man als Physiker in Deutschland erhalten kann, inklusive des angesehenen Leibniz-Preises. Auf seinen Stationen als Wissenschaftler in Kalifornien, Zürich und Konstanz sowie als Vizepräsident der Deutschen Forschungsgemeinschaft hat Mlynek Anregungen zur Erneuerung der Universität gesammelt. Zehn Jahre soll es dauern, bis das Ziel erreicht ist.“ (Spiewak, DIE ZEIT 45/2001)
\end{abstract}

Beide Leitungspersonen zeichnen sich nicht nur durch nachweislichen wissenschaftlichen Erfolg aus, sondern auch durch Auslandserfahrungen, die ihnen in besonderer Weise einen Außenblick auf die deutschen Universitätsstrukturen ermöglichten. Hermann und Mlynek stehen für den neuen Führungstyp, der sich nicht länger mit der zurückhaltend-repräsentativen Rolle des ,Grüßonkels“ bei festlichen Anlässen zufrieden gibt, sondern seine Universität im Wettbewerb stärken will und hierfür auch die ProfessorInnen hinsichtlich ihrer Leistungen stärker kontrolliert. Insbesondere Herrmann wird als Vertreter dieser ,neue[n] Spezies“ betrachtet, die „Gestaltungswillen mit Verkäuferqualitäten und Machtinstinkt" verbinde und die an den Universitäten zukünftig als „Sieger hervorgehen“ (Spiewak, DIE ZEIT 29/1999) werde. Die so betriebene Umsetzung der Reformen findet ohne Einschränkung die Zustimmung von Spiewak. Dabei handelt es sich nicht zuletzt um Veränderungen, die die individuelle wie kollektive Autonomie der ProfessorInnen betreffen: Sie müssen nun ihre individuellen Leistungen dokumentieren und werden in ihren Mitsprache- und Entscheidungsrechten eingeschränkt, indem „Wissenschaftsmanager“ an die Stelle von Repräsentationsgremien wie Akademischen Senaten treten, die „viel geredet", aber keine wirkliche Verantwortung für den Erfolg oder Misserfolg ihrer Universität übernommen hätten. Als Dekan habe Herrmann erlebt, wie seine 
Ideen von den „Gremien kleingehackt“ und sogar bewilligte Projekte durch das Verhalten der ProfessorInnen verhindert worden seien. Seine Maßnahmen seien folglich auch eine Reaktion auf frühere negative Erfahrungen:

„Gern erzählt Herrmann, wie in seiner Zeit als Dekan das geplante Biologicum in Garching scheiterte. Geld für das Projekt lag bereit, das Kultusministerium hatte zugestimmt. Doch das Biologicum wurde nie gebaut. Die beteiligten Professoren diskutierten die Idee zu Tode. ,Am Ende konnten sie sich nicht einigen, wem wie viele Quadratmeter zustehen sollen', erinnert sich Herrmann. ,Die kollektive Verantwortungslosigkeit‘ nennt Herrmann die Krankheit der deutschen Universität. Statt sich mit der Fakultät oder der Hochschule als Ganzem zu identifizieren, pflegen viele Professoren lieber ihre eigenen Pfründe." (ebd.)

So verdichtet sich der Eindruck eines dringenden, allumfassenden Modernisierungsbedarfs universitärer Strukturen. Die knappe Äußerung des damaligen Präsidenten des Bundesverbandes der Deutschen Industrie, Hans-Olaf Henkel, DER SPIEGEL bringt dies auf den Punkt:

„Das deutsche System akademischer Selbstverwaltung hat so viele Amateure mit Leitungs- und Managementaufgaben betraut, dass man sich wundert, warum es nicht schon längst zusammengebrochen ist." (zitiert in: Mohr, DER SPIEGEL 46/2000, S. 54).

Deutlich wird bis hierhin also, dass sich im Kontext der Befürwortung von Reformen in den journalistischen Beiträgen eine Tendenz zu einer Kollektivabwertung der Professorenschaft abzeichnet. Die Sortierung der ProfessorInnen in einen noch weit überwiegenden , alten ' und kritikwürdigen Typus, der in einer Beamtenmentalität verharrt und ein nur geringes Verantwortungsbewusstsein für die Lehre und den wissenschaftlichen Nachwuchs, aber auch generell für seine Universität zeigt, und einen favorisierten, aber noch seltenen ,neuen“ Typus, der sich aktiv für Reformen einsetzt und sich auf sie einlässt, ist unverkennbar. Die universitären Leistungen in der Lehre, die Funktionen von Bildung überhaupt, werden dabei vor allem über das für den Arbeitsmarkt zu vermittelnde Wissen, die Forschungsleistungen über die zu erlangende, ,internationale Wettbewerbsfähigkeit“ des deutschen Wissenschaftssystems beschrieben. Wie sieht dieses Bild dann zehn Jahre später aus? Halten die journalistischen Stimmen an ihrem Reformeifer fest? Feiern sie Reformerfolge? Oder ist die teilweise regelrechte Reformeuphorie einer Skepsis gewichen? 


\title{
2.4 Zehn Jahre später: Die journalistische Perspektive zwischen Reformeifer und Reformernüchterung
}

Schaut man sich die journalistischen Beiträge der Jahre 2012 und 2013 im Vergleich zum Themenspektrum zehn Jahre zuvor an, lässt sich zunächst für drei Themen feststellen, dass sie weitgehend aus dem journalistischen Blick geraten sind.

\section{„Bologna“}

Das gilt erst einmal - auf den ersten Blick am überraschendsten - für „Bologna“. Hier ergibt sich ein diffuses Bild. Insgesamt zeichnet die journalistische Berichterstattung, vor allem in DIE ZEIT, eine positive Entwicklung der Studienreform und stellt die Verbesserungen der Studienbedingungen seit Beginn des Prozesses in den Mittelpunkt, verweist in diesem Zuge jedoch auch mehrfach auf die als berechtigt erachteten Studierendenproteste des Jahres 2009 anlässlich der Reform-Umsetzungen. ${ }^{13}$ Vor allem neue - nicht nur im Kontext der „Bologna“Reformen stehende - Initiativen zur Lehrverbesserung, Lehr- und Lernkonzepte und ein konstatiertes gewachsenes Bewusstsein für die Relevanz ,guter' Lehre werden positiv hervorgehoben:

\begin{abstract}
„Mittlerweile [...] rückt die Lehre in immer mehr Fächern und Universitäten in den Vordergrund. [...] Der in Ehren ergraute Ordinarius, der seit Jahrzehnten vor gelangweilten Studenten aus derselben abgegriffenen Kladde liest - dieses Bild uninspirierter, die Bedürfnisse der Studenten missachtender Lehre sollte endgültig der Vergangenheit angehören, darin ist man sich an den Hochschulen inzwischen einig.“ (Etscheit, DIE ZEIT 44/2012).
\end{abstract}

„Die neue Botschaft“, so ZEIT-Autor Georg Etscheit, laute nun also: „Wer Arbeit in die Lehre steckt, wird belohnt" (ebd.). Die verstärkten Bemühungen der Universitäten um die Berücksichtigung studentischer Bedürfnisse und eine zu konstatierende ,Professionalisierung' der Hochschullehre ganz im Sinne der „Bologna“-Reformen finden großen Zuspruch. Dahin gehend scheinen viele der zuvor eingeforderten Veränderungen aus Perspektive der JournalistInnen also - endlich - eingetreten zu sein. Zugleich aber weicht die bis dahin vehemente Forderung nach Praxisbezug und Überwindung vermeintlich überholter Bildungs-

\footnotetext{
${ }^{13}$ Siehe hierzu u. a. Jan-Martin Wiardas „Streikbilanz“(DIE ZEIT 53/2009).
} 
ideale einer differenzierteren Perspektive, die auch die Kehrseiten und Grenzen der Reformbestrebungen thematisiert. Dies ist in den beiden betrachteten Jahrgängen nicht so präsent wie im Jubiläumsjahr des „Bologna“-Prozesses 2009 und seinem Folgejahr, scheint sich als journalistische Einschätzung aber weitgehend zu stabilisieren. Zehn Jahre nach Beginn des „Bologna“-Prozesses verbinden sich weiterhin geäußerte Reformforderungen mit vorher nicht gehörter Reformkritik in den journalistischen Beiträgen. Mit Blick auf die Situation an Schulen und Universitäten wird etwa die Kluft zwischen der propagierten „Bildungsrepublik“ und der Realität betont, und strukturelle Probleme wie Föderalismus sowie Unterfinanzierung - die Tatsache, „dass die Bundesrepublik vergleichsweise wenig Geld in Schulen und Hochschulen“ investiere (o. A., DER SPIEGEL 35/2010, S. 18) - werden kritisiert. Der Beitrag des SPIEGEL-Autors Thomas Darnstädt im Jahr 2010 über den „Bologna“-Prozess und dessen Umsetzung weist sogar eine deutliche Nähe zu den reformkritischen professoralen Stimmen in F\&L auf:

„Ohne dass das Ziel des Reformplans auch nur erkennbar war, beschloss die Kultusministerkonferenz in vorauseilendem Gehorsam, was die Bologna-Erklärung von 1999 so strikt gar nicht vorgesehen hatte: die Verpflichtung der Länder, ,flächendeckend" bis 2010 den europäischen Standard bis zum letzten Credit Point an ihren Universitäten umzusetzen.“ (Darnstädt, DER SPIEGEL 28/2010, S. 40)

Und weiter heißt es dort:

„Sechs Semester Schmalspur-Wissenschaft sollen nach dem Willen der bundesdeutschen Kultusminister den Geist der humboldtschen Universität ersetzen, um den Deutschland weltweit beneidet wurde. Kein Geist, nirgendwo: Generationen verunsicherter Nichts-richtig-Könner stehen der ,Bildungsrepublik Deutschland ${ }^{*}$ (Angela Merkel) ins Haus. [...] Nicht mehr Humboldt, Siemens setzt die Maßstäbe, das Bildungssystem ist in die Pflicht genommen, den Ausstoß von Ingenieuren zu vergrößern: eine Aufgabe, die früher überwiegend abseits der klassischen Universitäten von den Fachhochschulen erledigt wurde." (ebd., S. 40-42)

Diese dezidierte Kritik an „Bologna“ und der positive Rekurs auf Humboldt sind zwar nicht repräsentativ; dennoch zeigt sich insgesamt ein stärkeres Problembewusstsein. Es wird anerkannt, dass Ökonomisierung und Wettbewerb auch negative Folgen bzw. Schwierigkeiten zeitigen, die von den HochschullehrerInnen in ihrem beruflichen Alltag bewältigt werden müssen.

So wird dann auch die noch immer oftmals bemängelte Lehrqualität aufgrund von Unterfinanzierung und Wettbewerbsdruck in der Forschung als nachvollzieh- 
bar bewertet, statt sie lediglich zu kritisieren; und statt eines ,Professorenbashing “ werden positive Entwicklungen in den Vordergrund gerückt, die durch Initiativen - z. B. das „Bündnis für Hochschullehre“ - vorangetrieben würden. Dies bedeutet allerdings nicht, dass das Argumentationsmuster der ,Ewiggestrigen“ über die Zeit fallengelassen wurde. So wettert etwa Jan-Martin Wiarda angesichts der hohen Studienabbrecherquoten in den Ingenieurwissenschaften in DIE ZEIT (22/2012):

„Da glauben dann Professoren, es sei ein Ausweis ihrer Qualität, wenn $70 \%$ der Studenten in ihren Klausuren durchfallen; andere erachten ,Rausprüfen" als legitimes Mittel, um die ihres Erachtens viel zu hohen Anfängerzahlen auf ein erträgliches Maß zu stutzen. Gemeinsam ist beiden Gruppen die Auffassung, dass die Ingenieurwissenschaften nur etwas für eine absolute Elite seien, ganz sicher aber nicht für die ,Massen`. Wenn die am Studium scheitern, waren sie eben nicht schlau genug. Selber schuld.“

Wiarda kritisiert die Gleichgültigkeit, mit der Universitäten und insbesondere die Lehrenden ihrer Verantwortung gegenüber ihren Studierenden begegneten. Für Wiarda sind die Verantwortlichen für die hohen Abbrecherzahlen bzw. vielen „Abgeschreckt[en]“ klar ausgemacht, nämlich die ProfessorInnen:

\begin{abstract}
„Wie kann es sein, dass fast jeder zweite Ingenieurstudent an Deutschlands Universitäten sein Studium abbricht, und alles, was die verantwortlichen Professoren dazu zu sagen haben, erschöpft sich in müden Ausreden? [...] Als wäre es nicht bereits ein Drama, dass die Universitäten im Durchschnitt ein Drittel ihrer Bachelorstudenten vergraulen, ist es bei ihnen die Hälfte. Und sogar mehr [...] Eine Schande - und eine gesellschaftliche Riesendummheit noch dazu. Landauf, landab warnt die Wirtschaft vor einem angeblichen Ingenieurmangel, Zehntausende Stellen blieben jedes Jahr unbesetzt, heißt es. Mit allen möglichen Förderprogrammen und manchmal fragwürdigen Kampagnen versucht die Politik, mehr Schüler schon frühzeitig für die MINT-Fächer (Mathematik, Informatik, Naturwissenschaften und Technik) zu begeistern - doch die, die dann freiwillig kommen, werden von den Universitäten behandelt wie unnötiger Ballast, der nur beim Aufstieg zu intellektuellen Höhenflügen hindert.“ (ebd.)
\end{abstract}

Aber Wiardas Polemik kann genauso wenig wie Darnstädts Rekurs auf Humboldt als repräsentativ bezeichnet werden. Die spätere journalistische Perspektive ist insofern eine differenziertere und weniger tendenziöse, in deren Spektrum Kritik des Reformwiderstands und Parteinahme für die KritikerInnen der Reformen auf letztere kommen wir später erneut zu sprechen - gleichermaßen vertreten sind. 


\section{Juniorprofessur und W-Besoldung}

Die beiden anderen nunmehr eher randständigen Themen sind die Juniorprofessur und die W-Besoldung. Die Juniorprofessur scheint für die JournalistInnen an Bedeutung verloren zu haben und wird kaum thematisiert - vielleicht, weil sie die erhoffte durchschlagende Wirkung nicht gehabt hat. Die Zahl existierender Juniorprofessuren ist gering geblieben, die Habilitation ist weiterhin der vorherrschende Weg, um sich danach auf Professuren bewerben zu können sogar einige Juniorprofessuren haben sich habilitiert. Damit ist die Macht der ProfessorInnen über den wissenschaftlichen Nachwuchs, die eingedämmt werden sollte, nicht wirksam beschnitten worden. Die W-Besoldung wurde hingegen aufgrund des Urteils des Bundesverfassungsgerichts zur Verfassungsmäßigkeit der W2-Besoldung im Jahr 2012 noch mehrfach aufgegriffen. Sie verlor danach zwar ebenfalls an Aufmerksamkeit. Beim Thema der leistungsbezogenen Besoldung zeigt sich aber, dass die Perspektive auf ProfessorInnen und ihre Leistungen nicht von schlichten negativen Zuschreibungen bestimmt wird. Dies wird bereits bei dem journalistischen Blick auf das , alte' Besoldungssystem deutlich:

„Die Professoren waren die Ersten, an denen vor zehn Jahren ein Systemwechsel erprobt wurde. Mit der Einführung der ,W-Besoldung' fiel die Regel, dass ein Professor schon am Tag seiner Verbeamtung in einer Tabelle nachlesen konnte, wie sein ohnehin auskömmliches Gehalt bis zur Pension steigen würde. Ein Teil des Monatsverdienstes ist nun Verhandlungssache. Wer viel publiziert, Forscherpreise einheimst oder viele Doktoranden betreut, kann mehr Geld erzielen. Die anderen, die ,zu müden' $15 \%$, so die damalige Bundesforschungsministerin Edelgard Bulmahn, sollten munter gemacht werden." (Bartsch/Friedmann, DER SPIEGEL 7/2012, S. 46)

Wenngleich das frühere Besoldungssystem über ein per se ,auskömmliches Gehalt" und eine genaue Einschätzbarkeit charakterisiert wird, fehlt eine Gleichsetzung dieser privilegierten Situation mit Attributen wie Faulheit oder Bequemlichkeit. Zudem machen die SPIEGEL-Autoren Matthias Bartsch und Jan Friedmann deutlich, dass die ProfessorInnen die erste Beamtengruppe waren, die den Systemwechsel bei ihrer Besoldung in Kauf zu nehmen hatten. Die Klage des Marburger Chemie-Professors vor dem Bundesverfassungsgericht, von der der Artikel ausgeht, wird nicht kritisiert oder hinsichtlich ihrer Legitimität angezweifelt. Vielmehr lassen die Autoren kritische Stimmen in Bezug auf die W-Besoldung zu Wort kommen und greifen problematische Punkte auf - die Differenzen in der Höhe der Grundgehälter zwischen den Bundesländern beispielsweise, die mit der Föderalismusreform (2006) entstanden seien, aber auch 
die geringeren Chancen von ProfessorInnen bestimmter Disziplinen, ihr Grundgehalt durch Zulagen oder lukrative Nebenverdienste zu erhöhen:

„Den Spielraum für Zulagen bei einzelnen akademischen Stars haben sich die Länder erkauft, indem sie das Grundgehalt aller Professoren um rund $25 \%$ absenkten. [...] Unter der Kürzung leiden vor allem Geistes- und Sozialwissenschaftler, die nur schwer mit eingeworbenen Spenden glänzen oder sich durch Nebenjobs den Verdienst aufpäppeln können.“ (ebd.)

Ohne dass sich die Autoren dezidiert gegen die leistungsbezogene Besoldung aussprechen, ist der Artikel anschlussfähig an die Perspektive der KritikerInnen der Besoldungsreform; zumal abschließend auch der Geschäftsführer des DHV, Michael Hartmer, mit dem Argument der ohnehin starken Selektivität des Berufungsweges zu Wort kommt, die sich weiterhin im Festgehalt widerspiegeln müsse - „und nicht erst in den Zulagen“ (ebd.). ${ }^{14}$

In einem vom selben Anlass ausgehenden Beitrag greift auch ZEIT-Autor Wiarda disziplinäre Unterschiede in der Besoldung auf. Ohne das Modell des Leistungsanreizes per se abzulehnen, erkennt Wiarda - wie auch Bartsch und Friedmann - in der leistungsabhängigen Besoldung eine disziplinenspezifische Passung und damit eine nur scheinbare Fairness der Leistungsbelohnung. Denn während das Gehalt der ProfessorInnen früher ,automatisch mit dem Alter“ wuchs, gelte zwar seit der W-Besoldung „theoretisch“ das „Leistungsprinzip“:

\begin{abstract}
„Praktisch fehlen jedoch klare und damit einklagbare Kriterien für die Beurteilung und Belohnung von Leistung. Folge: Am Ende entscheidet über die Gehaltshöhe weniger das individuelle Können in der Forschung (geschweige denn der Einsatz in der Lehre), sondern vor allem der Marktwert des jeweiligen Fachs. So liegen zum Beispiel die Durchschnittsgehälter von Geistes- und Naturwissenschaftlern aufs Jahr gerechnet um Zehntausende Euro auseinander. Damit wird das Versprechen des Staates, akademische Leistung (und nur um die geht es) fair zu entlohnen, zur Worthülse. $\mathrm{Zu}$ Recht fordern nun die Verfassungsrichter ,klar definierte, vorhersehbare und erfüllbare Voraussetzungen". Alle sollen dieselbe Chance auf Leistungszulage haben. Erst dann wäre, wer keine Zulage bekommt, selber schuld. Und man könnte in jedem Fall von einer ,angemessenen Alimentation" sprechen." (Wiarda, DIE ZEIT 08/2012)
\end{abstract}

\footnotetext{
${ }^{14}$ Bestätigt konnten sich Kritiker der neuen Besoldung zudem durch eine kurze Meldung im Folgeheft (o. A., DER SPIEGEL 8/2012: 19) sehen. Dort wird mit Blick auf eine aktuelle Studie erwähnt, dass deutsche ProfessorInnen ,auch im internationalen Vergleich ein eher mäßiges Gehalt“ beziehen (,knapp vor Nigeria“).
} 
Thematisch fügt sich dies also in eine Kritik der Benachteiligung geistesund sozialwissenschaftlicher Disziplinen bei gleichzeitiger Befürwortung der Leistungsanreize ein. Die Besoldungsreform stellt im zweiten betrachteten Zeitraum allerdings einen randständigen, hier nicht weiter auszuführenden Gegenstand dar.

\title{
Forschung, Unterfinanzierung, Professorenautonomie
}

Im Vordergrund der journalistischen Perspektive der beiden hier betrachteten Jahre stehen vielmehr drei eng miteinander verflochtene Themen, wovon zwei - die Forschungsleistungen sowie die Unterfinanzierung der Universitäten - zehn Jahre vorher wenig angesprochen wurden, während das dritte die weiterhin stark diskutierte Professorenautonomie ist. Die Unterfinanzierung wird nunmehr als Problem angesehen, und für die beiden anderen Themen gilt, dass sie - anders als der generelle Tenor vor zehn Jahren war - vielschichtiger dargestellt und bewertet werden.

Mit Blick auf die Forschungsleistungen wird die Semantik eines leistungssteigernden Wettbewerbs vor allem unter Verweis auf die „Exzellenzinitiative“ gepflegt. Sie wird als begrüßenswerter Impuls bewertet, während die weiterhin vorherrschenden Vorstellungen der Gleichheit aller Universitäten das deutsche Wissenschaftssystem erlahmen ließen:

\begin{abstract}
„Mit dem Begriff ,Elite‘ tut man sich in Deutschland schwer. Deshalb wurde die ,Exzellenzinitiative', mit der Bund und Länder herausragende Forschungsprojekte, Doktorandenprogramme und Zukunftskonzepte von Universitäten mit insgesamt 4,6 Mrd. € fördern, schon immer etwas argwöhnisch beäugt. [...] [Hier] offenbart sich ein unschöner Geist: der Geist der Gleichmacherei. [...] Forschung aber hat mit Leistung zu tun, mit Wettbewerb - und auch mit Bestenauslese.“ (Etzold, DIE ZEIT 31/2013)
\end{abstract}

Der eingeforderte Abschied von der „Gleichmacherei“ mit der sprichwörtlichen ,Gießkanne“ als Förderprinzip will stattdessen einzelne Einrichtungen zu ,Leuchttürmen' machen, die die deutsche Wissenschaft international konkurrenzfähig werden lassen.

Hinsichtlich der Hochschulfinanzierung werden zunächst positive Entwicklungen gewürdigt, die angesichts der Investitionen der Hochschulpolitik in die universitäre Forschung, aber auch Lehre bereits verzeichnet werden konnten. „[V]iel ist erreicht worden in den vergangenen zehn Jahren“, wie Marion Schmidt und Spiewak in DIE ZEIT (25/2013) schreiben:

„Besonders in der Forschung standen deutsche Universitäten noch nie so gut da wie heute. Die ,Exzellenzinitiative“ sowie diverse Förderpakete von Bund und Ländern 
zu Forschung, Lehre und Studienplätzen haben viel Geld ins System gespült, die öffentlichen Ausgaben für die Hochschulen sind zwischen 2000 und 2012 von rund 17 auf knapp 25 Mrd. Euro gestiegen. Viele Hochschulen haben das Geld und die ihnen vielerorts gewährte Autonomie über Haushalt und Personal genutzt, um ihre Forschungsstrukturen auszubauen, Graduiertenschulen für die Ausbildung des Nachwuchses einzurichten und Kooperationen mit außeruniversitären Forschungszentren zu verstärken. Deutschland ist international wettbewerbsfähiger geworden. Nun reisen selbst Leiter amerikanischer Universitäten an, um sich die Doktorandenausbildung hierzulande anzuschauen. Zudem gelingt es immer häufiger, exzellente Wissenschaftler aus dem Ausland anzuwerben oder deutsche Wissenschaftler zurückzuholen.“

ZEIT-Journalist Andreas Sentker spricht gar von einer „historischen Ausnahmesituation “ (42/2013), in der die Wissenschaft in Deutschland sich nun befände:

„Hochschulpakt, ,Exzellenzinitiative‘, Pakt für Forschung und Innovation - nie zuvor haben wir so viel Geld in Forschung gesteckt. Deutsche Institute sind beim Rennen um die besten Köpfe konkurrenzfähig. “

Als Kehrseite dessen wird aber nun auch die Unterfinanzierung des deutschen Hochschulsystems angesprochen, die nicht nur zu schlechten Betreuungsrelationen in der Lehre führe, womit der Erfolg von „Bologna“ gefährdet werde, sondern auch einem Exzellenzstreben in der Forschung Fesseln anlege und generell zu einer zunehmende Ökonomisierung der Universitäten führe. Aus Anlass einer Millionenspende der Schweizer Bank UBS - 100 Mio. Schweizer Franken - an die Universität Zürich im Jahr 2012 wird etwa von Mathias Daum (DIE ZEIT 49/2013) unter dem Titel „Die gekaufte Uni“ vor einer sich verstärkenden Drittmittelabhängigkeit von wirtschaftlichen Interessen gewarnt - eine Gefahr, die bei den im Vergleich zu Zürich ungleich schlechter grundfinanzierten deutschen Universitäten entsprechend viel höher sei. Der Einfluss politischer Forschungslenkung durch Förderprogramme wie auch die "Exzellenzinitiative“ wird dabei als potenziell nicht weniger problematisch angesehen. So wird die Autonomie der Hochschulen und ihrer ProfessorInnen wiederholt zum Thema gemacht - mit Bezug auf letztere nun aber nicht als problematisch verselbstständigte, sondern gefährdete Autonomie.

Insbesondere in DIE ZEIT häufen sich kritische Beiträge zur ,gekaufte[n] Wissenschaft" (Kohlenberg/Musharbash, DIE ZEIT 32/2013), in denen auch das bis dahin wenig gewürdigte, sondern als Professorenideologie abgetane Forschungsethos in den Blick rückt. Die Befürchtung der Ablösung wissenschaftlicher Neugierde und intrinsischer Motivation durch ökonomische Interessen und einen sich unter ProfessorInnen etablierenden „Unternehmergeist“ wird gegen eine zu starke Ausrichtung auf Drittmittel und Industriekooperationen angeführt. Die ZEIT-AutorInnen Kerstin Kohlenberg und Yassin Musharbash konstatieren 
eine mittlerweile ,eigenartige Gewöhnung an die Ökonomisierung in der Forschung“(DIE ZEIT 32/2013):

\begin{abstract}
„Wissenschaft muss profitorientiert sein. Dieser Satz wäre wohl noch vor wenigen Jahren von einem Großteil der deutschen Wissenschaftler vehement zurückgewiesen worden. Inzwischen aber gibt es offenbar eine eigenartige Gewöhnung an die Ökonomisierung der Forschung. In einer Zeit, in der immer mehr Schulen, Krankenhäuser und Theater privatwirtschaftlich geführt werden, scheint es, als ob die Hochschulen zunehmend akzeptieren, dass Wissenschaft nicht in erster Linie Erkenntnis bringen muss, sondern Geld."
\end{abstract}

Eine solche Sichtweise der Universitäten wird als höchst problematisch eingestuft. Industriegelder erzeugten Abhängigkeiten, die nicht zuletzt in einer Beliebigkeit der Forschungsergebnisse resultierten, denn „Auftraggeber überleg[t]en sich, welche Aussagen sie im öffentlichen Diskurs stärken wollen, und [...] such[t]en [...] sich [dann] das passende Institut aus“ (ebd.).

Während also das wissenschaftliche Ethos sukzessive erodiere, habe ein neuer Professorentypus die finanzielle Attraktivität der Auftragsforschung für sich entdeckt, die er durchaus zu nutzen wissen:

„Es ist etwas Erstaunliches passiert, seit die Wirtschaft in die Universitäten gelangt ist: Auf den Fluren der Hochschulen begegnet man neuerdings nicht nur Managern und Unternehmern - sondern auch anderen Professoren als früher. Ein neuer Prototyp von Wissenschaftler ist entstanden, einer, der sich nicht so sehr als unabhängiger Forscher sieht, sondern eher als pragmatischer Dienstleister seines Auftraggebers.“ (ebd.)

Dass dieser "neue Prototyp“ dem Ansehen der „gesamte[n] Wissenschaft“ schade, sehen die AutorInnen durch eine abnehmende Glaubwürdigkeit wissenschaftlicher Forschungsleistungen bestätigt. An die Stelle gesellschaftlicher Anerkennung für die erbrachten Leistungen trete ein zunehmendes Misstrauen: „Denn fragwürdige Studien und Forscher, die sich an den Bedürfnissen des Marktes ausrichten, haben die Macht, den ganzen Wissenschaftsbetrieb in Misskredit zu bringen.“(ebd.) $)^{15}$

\footnotetext{
${ }^{15}$ Dass das „öffentliche Bild von der unabhängigen Wissenschaft“ bereits „Kratzer bekommen" habe, sehen die AutorInnen auch durch eine Meinungsumfrage der Europäischen Kommission zur Glaubwürdigkeit wissenschaftlicher Ergebnisse bestätigt. Das Fazit der Studie wird so zusammengefasst: „Die Europäer gehen mit großer Entschiedenheit davon aus, dass man nicht darauf vertrauen kann, dass Wissenschaftler bei kontroversen wissenschaftlichen und technischen Problemen die Wahrheit sagen, weil sie zunehmend von den Fördermitteln der Industrie abhängig sind.“ (ebd.)
} 
Zwar wird Wettbewerb keineswegs abgelehnt. Doch werden vermehrt die negativen Konsequenzen eines überzogenen Wettbewerbsstrebens sowie eines durch Ökonomisierung ausgelösten Wettbewerbsdrucks thematisiert - und zwar als Gefährdungen unabhängiger und nur so vertrauenswürdiger Forschung.

Die Professorenautonomie bleibt in der journalistischen Perspektive dennoch ein ,zweischneidiges Privileg'. Generell gilt, und das ist der wichtigste Wandel der journalistischen Sicht der Dinge, dass die zehn Jahre früher geäußerte Kritik an einer selbstherrlich genutzten Professorenautonomie so pauschal nicht aufrechterhalten wird. In DER SPIEGEL wie auch in DIE ZEIT finden sich vielmehr nun differenziertere Beiträge bzw. sowohl Beiträge, die wie zwölf Jahre zuvor problematische Seiten von Autonomie hervorkehren, als auch solche, in denen Autonomiegefährdungen angesprochen werden. Tendenziell werden bezüglich der Forschung, wie gerade angesprochen, die Autonomiegefährdungen betont, bezüglich der Lehre hingegen weiterhin die Probleme zu weitgehender Autonomie, wenn es etwa um die Betreuung von Studierenden geht. In diesem Zusammenhang wird auch die Doktorandenbetreuung problematisiert - in den Jahren 2012 und 2013 insbesondere anlässlich der Diskussion von Plagiatsfällen prominenter PolitikerInnen. Allen voran wurden die Causae Karl Theodor zu Guttenberg und Annette Schavan herangezogen, um zu zeigen, so die journalistische Bewertung, dass Autonomiemissbrauch sich auch in mangelnder Sorgfalt bei der Begutachtung von Prüfungsleistungen zeige. Weiterhin wird beim Umgang mit aufgedeckten Plagiaten hinterfragt, ob die immer wieder beteuerten "Selbstreinigungskräfte der Wissenschaft" (Spiewak, DIE ZEIT 07/2013) ausreichten oder ihr externe Kontrollen auferlegt werden müssten. Von der Doktorandenbetreuung und -bewertung wird teilweise ein Generalverdacht auf Prüfungsaktivitäten und Lehrengagement hergeleitet. So fragt Spiewak in DIE ZEIT provokant, ,warum man [...] mit Hingabe Ideale, die weit in die Vergangenheit zurückreichen, am liebsten bis zu Wilhelm von Humboldt [beschwört]“ (ebd.), statt das eigene Arbeiten auf den Prüfstand zu stellen. Die fast ausnahmslos ,exzellenten und beinahe exzellenten Arbeiten“ lösten Zweifel an der professoralen Sorgfaltspflicht aus, die „Selbstreinigungskräfte“ der autonomen Wissenschaft seien offenbar unzureichend und diese „gefangen in der internen Logik“ (ebd.):

„In den vergangenen Wochen der Debatte um Doktortitel und Plagiate schwenkten Professoren und Standesvertreter wieder einmal besonders eifrig das große Weihrauchfass; sie beschworen die ,Standards" und die ,Selbstreinigungskräfte der Wissenschaft', sangen das Hohelied von der ,Autonomie " und von der ,Freiheit der Forschung'. Im Umgang mit den Plagiatsvorwürfen entpuppte sich dies als Vernebelungsstrategie. Denn von welchen wissenschaftlichen Standards war da die 
Rede? Für die Bewertung von Plagiaten fehlen der Wissenschaft ja offenbar, wie sich zeigte, die eindeutigen Maßstäbe. [...] Und was die ,Selbstreinigungskräfte der Wissenschaft ‘ angeht, bleibt festzuhalten: Sämtliche Plagiatsfälle der vergangenen Jahre wurden von Hobbyrechercheuren im Internet aufgedeckt.“ (ebd.)

In der Folge werden die professoralen Klagen über die ihnen auferlegten Rechenschaftspflichten in Forschung und Lehre - die behauptete ,grassierende ,Evaluitis“, permanente Begutachtung und Befragung" (ebd.) - daher auch als unangebracht und übertrieben eingestuft: „Viel wäre gewonnen, [...], wenn die Hochschulen ihre Hausaufgaben machten und sich ein professionelles Controlling zulegen würden“ (ebd.), so Spiewak.

Trotz solcher Beiträge, die das bereits zehn Jahre früher geläufige Muster reaktivieren, fallen nun auch Stellungnahmen in DIE ZEIT und DER SPIEGEL auf, in denen die bereits realisierten und noch zu realisierenden Reformvorhaben zwar zu notwendigen und richtigen Schritten erklärt werden, dabei allerdings auf die frühere Professorenschelte verzichtet wird. Stattdessen werden HochschullehrerInnen als Personen dargestellt, die mit einer hohen beruflichen Belastung umgehen müssen und dabei neuen Instrumenten der Bewertung und Steuerung ausgesetzt sind, die sie auch kritisieren dürfen. In dieser nun zur Kenntnis genommenen Kritik rücken dann auch Akteure aus Politik und Wirtschaft in den Blick, deren Einflussnahme auf die Universitäten nicht durchgehend als hilfreich und legitim eingestuft wird.

So wird etwa der professorale Protest gegen Rankings - Hintergrund ist hier der Protest einiger Fachverbände gegen das CHE-Hochschulranking - nicht einfach als schlichte Abwehr jeglicher externer Bewertung dargestellt. Zum einen macht der SPIEGEL-Autor Friedmann deutlich, dass sich der Protest nicht auf einzelne Universitäten oder spezielle Disziplinen beschränke. Die professorale Kritik wird deshalb ernster genommen, weil sie sich ebenso in ,nüchterne[n] Fächer[n]“ (DER SPIEGEL 49/2012, S. 50) findet, also auch in den Naturwissenschaften, die - dies ist der implizite Bedeutungsgehalt - nicht im Verdacht stehen, besonders rückwärtsgewandt zu sein. Zum anderen wird deutlich, dass die gegen das Ranking vorgebrachten Argumentationen differenziert sind und keineswegs pauschal für eine mangelnde Leistungsbereitschaft sprechen. Denn neben methodischen Vorbehalten kommt auch der professorale Kritikpunkt zur Sprache, durch die Einbindung in neue Formen der Steuerung und Konkurrenz von einer Form der Aufgabenerfüllung abgehalten zu werden, die wissenschaftlichen Kriterien und den Erwartungen an das Amt des Hochschullehrers entspricht: 
„Er [ein Chemieprofessor, der sich in einem Fachorgan kritisch zum Ranking geäußert hatte] fühlt sich wie ein Gemüsebauer, dem keine Zeit gelassen wird, sein Feld ordentlich zu bestellen: Die Früchte werden so häufig kontrolliert, klassifiziert, kategorisiert, dass sie nicht zur Reife gelangen können. Die zahlreichen Evaluationen und Rankings, beklagt der Professor, ließen ihm nicht mehr die nötige Ruhe." (ebd.)

Und gegen Ende des Artikels heißt es allgemeiner:

\begin{abstract}
„Der Verdruss der Professoren rührt nicht allein von Rankings. Viele Wissenschaftler fühlen sich im Klammergriff kleingeistiger Administratoren. Sie haben den Eindruck, dass sie vor lauter Bewertungen und Drittmittelanträgen nicht mehr zum Kerngeschäft kommen: zu Forschung und Lehre. Radikale Kritiker plädieren für eine Kehrtwende. ,Kooperation ist leistungsfördernder als Wettbewerb“, sagt Dieter Lenzen, Präsident der Universität Hamburg.“ (ebd.)
\end{abstract}

Damit wird Kritiken Raum gegeben, die sich nicht nur auf Rankings, sondern ebenso auf Drittmittelanträge beziehen und insofern darauf hinweisen, dass auch die Forschungsförderung durch externe Geldgeber folgenreich ist. Durch die zitierte Äußerung von Lenzen bekommt diese Lesart tendenziell noch mehr Gewicht: Mit ihm spricht sich sogar eine Leitungsfigur, die längere Zeit nicht gerade als Reformgegner galt, im Sinne der Leistungsförderung für eine ,Kehrtwende' in der grundlegenden Logik des Umgangs mit den Universitäten und ProfessorInnen aus. Zudem legt die Darstellung der ProfessorInnen ein Amtsethos nahe, denn es geht in den zitierten Äußerungen nicht ,nur' um die persönliche Autonomie gegenüber „kleingeistige[n] Administratoren“, sondern auch um die Verantwortung für die Lehre.

Im journalistischen Diskurs lassen sich somit im Zeitverlauf, trotz der nach wie vor vertretenen Reformsemantik, deutliche Differenzierungen ausmachen. Während 1999-2001 die Befürwortung des Neuen und die Zustimmung zu den wissenschaftspolitischen Zielen dominierte, ist dieser ,Reformeifer' einer teils nachdenklicheren Perspektive gewichen.

\title{
2.5 Verletzungen auf ganzer Linie: Zweiter Teil der professoralen Perspektive
}

Im letzten Schritt unserer Analyse des medialen Diskurses richten wir unseren Blick nun wieder - und damit schließt sich der Kreis - auf die professoralen Stimmen in F\&L. Wir hatten bereits deren konstant gebliebene ablehnende 
Haltung zu „Bologna“ geschildert. Nun betrachten wir die weiteren, insbesondere die Forschung betreffenden Reformauswirkungen. Die verschiedenen Beiträge spiegeln insgesamt eine ähnlich gravierende Verletztheit wie in den Angelegenheiten der Lehre durch die empfundene Missachtung der eigenen beruflichen Identität und der erbrachten Leistungen wider. Dies gilt bereits für die Jahre 2000 und 2001, in denen - noch am Anfang der Reformen - grundsätzlicher auf die Relevanz von Curiositas und Autonomie verwiesen wird. Die zehn Jahre späteren Beurteilungen sind dann erfahrungsgesättigter, ohne irgendwo größere Revisionen zu machen. Die anfänglichen Befürchtungen haben sich bestätigt.

\title{
Misstrauen
}

Sehr grundsätzlich wird das von politischer Seite artikulierte - und auch in den früheren journalistischen Beiträgen deutlich zum Ausdruck kommende - Misstrauen gegenüber den Universitäten und HochschullehrerInnen beklagt:

\begin{abstract}
,[D]en unbefangenen Beobachter [muß] schon irritieren, mit welcher Energie in der gegenwärtigen Hochschulpolitik der Versuch unternommen wird, die Universitäten öffentlich in Verruf zu bringen. So müssen sich ausgerechnet die Universitäten und hier vor allem die Professoren den ständig wiederholten Vorwurf gefallen lassen, ewig Gestrige zu sein, die sich dank ihrer Unbeweglichkeit und dank ihres Beharrungsvermögens dem Neuen schlechthin verweigern." (Schiedermair, F\&L 5/2001, S. 236)
\end{abstract}

Während sich Schiedermair hier auf negative Zuschreibungen in Diskursen bezieht, geht der seinerzeit amtierende Rektor der Universität Wuppertal, der Soziologe Volker Ronge, konkreter auf NPM - hier: Zielvereinbarungen - ein. In diesen drücken sich für ihn nicht nur das Misstrauen gegenüber der Wissenschaft und deren zunehmende Ökonomisierung aus, sondern manifestiert sich auch die wachsende Asymmetrie zugunsten der politischen Sphäre:

„Dass gleichwohl sie selbst die Musik bestimmt, die sie bezahlt, dass sie mitnichten auf den Steuerungsanspruch verzichtet, rechtfertigt die Politik mit (ihrer monopolistischen) Repräsentation öffentlicher Interessen, ihrer Verantwortung für die Verwendung öffentlicher Haushaltsmittel; die Exekutive verweist auf die ihr vorgesetzte Legislative und diese aufs Volk. [...] Dagegen steht allerdings eine Konzeption, in der die Wissenschaft gegenüber Gesellschaft und Gemeinwohl den gleichen, den parallelen Rang einnimmt wie die Politik. [...] Der Modus der Zielvereinbarungen signalisiert, dass die Politik diesem Modell nicht folgen will, dass sie nun anders als bisher steuern will: mit Geld." (Ronge, F\&L 4/2000, S. 189) 
In beiden Äußerungen wird vermittelt, dass Universitäten bzw. HochschullehrerInnen ihrer Verantwortung für das Gemeinwohl durchaus ohne weitere Kontrolle und gemäß dem eigenen beruflichen Ethos nachkämen.

Was bei Schiedermair und Ronge noch vergleichsweise implizit bleibt, wird im Kontext der Kritik an der leistungsbezogenen Besoldung weitaus expliziter. Diese wird zu einem wesentlichen Ausgangspunkt dafür, das berufliche Selbstverständnis gegenüber einer Degradierung durch die Politik zu verteidigen. Herausgestellt werden dabei die Autonomie bei der Berufsausübung und die intrinsische Motivation, durch die der Bezug auf die berufliche Tätigkeit maßgeblich bestimmt werde. Die Vorstellung, monetäre Anreize würden den Einzelnen zu mehr Leistung motivieren, wird vor diesem Hintergrund scharf zurückgewiesen. Während es im Positionspapier des DHV zur Reform des Dienstrechts heißt, dass „Professoren [...] die Wissenschaft zum Beruf gemacht [haben], um selbstbestimmt arbeiten zu können, nicht um möglichst viel Geld zu verdienen“ (DHV, F\&L 7/2000, S. 350), richtet sich der Rechtswissenschaftler Thomas Hoeren in seinem Kommentar an die maßgeblich verantwortlichen PolitikerInnen der Besoldungsreform, insbesondere aber an die damals amtierende Bundesministerin Bulmahn:

\begin{abstract}
„Vor allem frustriert uns das hinter Ihrem Reformplan stehende Bild des Hochschullehrers. Wir sind solche geworden, weil wir Spaß am Kontakt zu jungen, wissbegierigen Menschen haben, weil wir Forschung und darauf aufbauende Lehre lieben. [...] Wie entfernt muss jemand von der Hochschullandschaft sein, um so etwas vorzuschlagen! Wer mit Besoldung winkt, zerstört an der Hochschule alles, setzt auf die einzige Karte, die an den Forschungseinrichtungen gerade nicht zieht. Mehr Geld für Forschung und Lehre - ja; aber ein paar Hundert Mark mehr im Beutel des Profs - pfui, bäh! Sie nehmen uns die Luft zum Atmen, wenn Sie auf den schäbigen Taler und die in dieser Sache leicht zu mobilisierende öffentliche Meinung setzen." (Hoeren, F\&L 6/2000, S. 297)
\end{abstract}

Hoeren, der aus der Perspektive eines Nachwuchswissenschaftlers spricht, kritisiert die politische Prämisse einer materiellen und extrinsischen Motivation von ProfessorInnen massiv. Geld soll nicht den Einzelnen belohnen, sondern bessere Forschung und Lehre ermöglichen und insofern dem Gemeinwohl dienen. Zugleich zeigt sich bei ihm aber auch das Bedürfnis nach symbolischer Anerkennung, das im Wunsch nach einer angemessenen Besoldung - und zwar ohne dass man sich einen Teil davon erst durch das, was als Leistung gezählt wird, verdienen muss - zum Ausdruck kommt. Hoeren empfindet als „beschämendsten Aspekt“ der W-Besoldung die dadurch zum Ausdruck gebrachte Degradierung seiner Person und Leistungen, ohne dass man ihm 
Gelegenheit gegeben habe, angehört zu werden: „Sprechen Sie mit uns, Frau Ministerin! Wir sind keine Faulenzer, DiMiDos, Gutachtenscheffler, Hinterwäldler." (ebd.)

Die mit der W-Besoldung unterstellte materielle Orientierung wird noch in anderen Beiträgen kritisiert. Reputation und Geld seien nicht unwichtig, aber nachrangig - wenn die von Gratifikationen unabhängige eigene Begeisterung fehle, sei eine Tätigkeit als ForscherIn kaum möglich oder zumindest kaum als dauerhaft und erfolgreich vorstellbar. So schreibt der Rechtswissenschaftler Peter Schüren:

„Natürlich freuen Ehrungen, Geld, Status usw.; aber sie unterstützen nur. [...] Die Frauen oder Männer, denen Passion zur Wissenschaft fehlt, die diesen tiefen Antrieb nicht haben, kommen nicht weit - da helfen weder Geld noch gute Worte.“ (Schüren, F\&L 5/2000, S. 233)

Das ökonomische Desinteresse wird nicht nur mit intrinsischer Motivation und Gemeinwohlorientierung belegt, sondern auch mit der Ausrichtung an der für die berufliche Identität bedeutsamen immateriellen Anerkennung durch FachkollegInnen oder eine interessierte Öffentlichkeit. HochschullehrerInnen verdienten zwar mitunter durch Vorträge in Wirtschaft oder Politik dazu, innerhalb der wissenschaftlichen Sphäre sei diese Form der Gratifikation von Leistungen aber gerade irrelevant oder sogar verpönt:

\begin{abstract}
„Wenn ich einen Auftrag in der Privatwirtschaft übernehme, dann bestehe ich darauf, dass man mich dort so bezahlt, wie es üblich ist. Wenn mich eine andere Universität einlädt, werde ich selbstverständlich nicht an ein Honorar denken. Dann freue ich mich bereits, wenn man mir die Reisekosten bezahlt und mich irgendwo unterbringt, notfalls kann ich das aber auch selbst übernehmen. Das hat mit dem Selbstverständnis meines Standes zu tun. Man macht das eben so. Agiert man anders, grinsen die Kolleginnen und Kollegen.“(ebd.)
\end{abstract}

Es wird also mit einer Selbststeuerung qua beruflichem Selbstverständnis argumentiert, das wirksam durch die Scientific Community kontrolliert und sanktioniert werde.

In diesem Kontext wird auch die Machtzunahme politischer Entscheidungsträger gegenüber der akademischen Selbstverwaltung kritisiert. So beklagt Schiedermair den neuen autoritären Stil gegenüber den Universitäten mit scharfen Worten: 
„Was die Universitäten nicht einsehen wollen, muß ihnen eben beigebracht werden. Deswegen wird die Bildungs- und Hochschulpolitik zurzeit in nur mäßig demokratischer Gesinnung gewöhnlich mit erhobenem Zeigefinger und unverkennbaren Drohgebärden betrieben. Steuerung ist das Zauberwort, mit dem die unbotmäßigen Universitäten zur Räson gebracht werden sollen. Es hat in der vom Grundgesetz gestalteten Gesellschaftsordnung noch niemals eine Zeitspanne gegeben, in der die Universitäten in so starkem Maß der Fremdsteuerung durch ihre staatlichen Träger ausgesetzt waren, wie sie heute geradezu üblich geworden ist. [...] Daß all das aber ausgerechnet mit dem Schlagwort der Autonomie politisch verkauft wird, läßt doch einige Zweifel an der Redlichkeit der Verkäufer zu. (Schiedermair, F\&L 5/2001, S. 237)

Die empfundene Drangsalierung durch äußere Mächte wird dadurch noch schlimmer, dass sich in den Universitäten Erfüllungsgehilfen in Gestalt von immer mehr Leitungsfiguren gefunden haben. Diese in den journalistischen Beobachtungen als Hoffnungsträger der Reformen porträtierten Akteure erscheinen in den professoralen Stellungnahmen geradezu als Verräter. So spricht Schiedermair von einer

„wachsende[n] Zahl von Funktionären, die mit dem Königsmantel des Managers längst ihren Einzug in die Universität gehalten haben, um im Schutz der gesetzlich verordneten zentralen Leitungsgewalt von dem zu träumen, was sie für Macht halten." (ebd., S. 236)

Zwölf Jahre später, im zweiten Zeitraum unserer Analyse also, weist der Kulturhistoriker Günther Lottes dezidiert polemisch auf eine neue „politische Klasse“ hin, die sich nun innerhalb der Universitäten etabliert und sich durch die Konzentration auf den Ausbau ihrer eigenen Macht zunehmend von der eigentlichen Aufgabe, als Sachwalter ,guter' Forschung und Lehre zu wirken, entfernt habe:

„In nachgeordneten verfassten Gemeinschaften wie der Universität hat die Hochschulgesetzgebung der vergangenen Jahre den zugegebenermaßen ständischen Gleichheitsanspruch der Hochschullehrergemeinschaft vernichtet und die Entstehung einer politischen Klasse gefördert, die das akademische Personal zügig und effizient unterwirft. [...] Ihr geht es um die Ausübung von Macht, nicht um Wissen oder Wissensweitergabe. Ihr ist weder das studentische Publikum der Vorlesung und des Seminars noch das kollegiale Publikum von Tagungen und vergleichbaren Veranstaltungen genug. [...] Präsidenten, Vizepräsidenten und Dekane agieren wie römische Prokonsuln. Man tröste sich mit Ciceros ,Orationes in Verrem“. Aber das geschieht alles unter ärmlichen Umständen. Denn die politische Klasse in der Wissenschaft ist eine nachgeordnete, ja zweitrangige politische Klasse, der die hohe 
politische Klasse der großen Politik nur widerwillig Mittel zuweist, im Norden der

Republik deutlich weniger als im Süden.“ (Lottes, F\&L 2/2013, S. 128)

Während Lottes zuletzt eher den subalternen Status dieser Klasse gegenüber den ,eigentlichen' Machthabern in den Ministerien betont, zielt die Kritik des Soziologen Jörg Michael Kastl genau auf den Machtzuwachs von Hochschulleitungen, der sich anhand des Entwurfs eines neuen Landeshochschulgesetzes in Baden-Württemberg abzeichne. Entgegen den offiziellen Verlautbarungen werde das Modell der ,unternehmerischen ' Universität mit dem Gesetzesentwurf noch zugespitzt und würden die Aufgaben und Befugnisse von DekanInnen und Fachbereichen zugunsten des Rektorats weiter eingeschränkt:

„Mehrfach fällt das Stichwort ,Autonomie‘. Nur geht es da nicht um die Autonomie derer, die im ,operating core" arbeiten und studieren, sondern um die der ,monokratischen Leitungsorgane" (Bogumil) des ,Vorstands', der nun wieder ,Rektorat " heißen, aber trotzdem die Hochschule ,stark steuern' soll.“ (Kastl, F\&L 12/2013, S. 996)

Und weiter:

„Das ist ein Gesetz, das endgültig jede Machtbalance zwischen den dezentralen und zentralen Organen der Hochschule zerstört und den Fakultäten das letzte Refugium nimmt, das sie noch hatten, nämlich ihre genuine fachliche Zuständigkeit für Forschung und Lehre.“ (ebd., S. 998)

Das Thema der Leitungsebene bleibt insofern über die Jahre konstant kritisch.

\section{Forschungsautonomie}

Das Pochen auf Autonomie in der Forschung gewinnt im Zeitverlauf sogar noch an Bedeutung. In den Beiträgen um die Jahrtausendwende wird Autonomie als Voraussetzung für einen ergebnisoffenen Forschungsprozess betont, bei dem die inhärente Ambivalenz jeglichen Erkenntnisstrebens - kein Wissensgewinn ohne Zweifel - anerkannt wird. Konkret bedeutet dies, die nötige zeitliche Dauer sowie auch Fehlschläge und Irrtümer als konstitutive Merkmale von wissenschaftlichem Erkenntnisstreben - als Preis für bahnbrechende Innovationen - zu akzeptieren.

Autonomie wird sodann auf die forschenden WissenschaftlerInnen bezogen. Ihnen müsse die subjektive Haltung einer gewissen Risikofreude und Kreativität, ohne die neue Erkenntnisse kaum denkbar seien, ermöglicht werden. Mit anderen Worten wisse die Forscherin am besten, welche Themen, Theorien oder Methoden sie am besten beherrscht, sodass sie insofern möglichst frei in ihrer 
Wahl sein sollte. So wendet sich der Wissenschaftshistoriker Klaus Fischer im Jahr 2000 gegen ein „organisatorisches und planerisches Korsett“, das dem „eigenen Impetus“ des Forschers und seiner gewachsenen Urteilskraft hinsichtlich der Themen- und Methodenwahl unterlegen sei:

\begin{abstract}
„Die historischen Erfahrungen zeigen, dass die Wissenschaft am besten gedeiht, wenn sie ihrem eigenen Impetus folgen darf und nicht in ein organisatorisches und planerisches Korsett gezwängt wird. Keiner weiß besser als der einzelne unabhängige Forscher, wo die interessanten und aussichtsreichen Probleme seines Spezialgebietes liegen, welches Wissen und welche Methoden man für ihre Lösung heranziehen könnte und nach welchen Kriterien die Lösungsvorschläge zu bewerten sind.“ (Fischer, F\&L 1/2000, S. 15)
\end{abstract}

Das Prinzip, wissenschaftliche Forschung zunehmend gerade aktuellen gesellschaftlichen Problembezügen sowie den Normen von Effizienz und Wettbewerbsdenken zu unterwerfen, wird darüber hinaus mit einer Gefährdung der Breite und Fundiertheit der Wissensbestände verbunden: Die drohende Verlagerung auf Routine- und Mainstreamforschung, die abschätzbare Ergebnisse zeitige, bedeute letztlich eine Engführung, die den jeweiligen Fachdisziplinen schade. Das Ideal einer übergeordneten Linie oder Forschungsperspektive, die die einzelnen Projekte im Laufe der Forscherinnenbiografie miteinander verbindet, wird in diesem Zusammenhang bereits eher in der Vergangenheit verortet:

„Es wird zunehmend schwieriger, ein Forscherleben zu leben, das von einer großen, verbindenden Idee geprägt ist, in dem die einzelnen Projekte [und] Aufsätze [...] ein zusammenhängendes Ganzes bilden.“ (Neuhäuser, 11/2000, S. 590)

Der Literaturwissenschaftler Rudolf Neuhäuser geht von den Bedrohungen eines solchen „Forscherlebens“ aus, genauer: von der zunehmend an ProfessorInnen gerichteten Forderung, als WissenschaftsmanagerInnen zu agieren und sich mit den Forschungsinteressen mehr an gesellschaftlich definierten Nützlichkeiten und Aktualitäten zu orientieren. Zum anderen wird aber auch eine schädliche Transformation der Haltung und Orientierung von ForscherInnen, wie nachfolgend von Schiedermair, problematisiert: „An die Stelle der wissenschaftlichen Kreativität rückt jetzt die Tüchtigkeit des
Verkäufers, die - auch wenn es gelegentlich durchaus geschäftstüchtige Wissen-
schaftler gibt - als solche mit der wissenschaftlichen Kreativität nichts gemein hat.“
(Schiedermair, F\&L 5/2001, S. 236) 
Es drohe die Gefahr einer zunehmend - wie man sagen könnte - ,gesellschaftlich korrekten' Forschung, bei der intrinsische Interessen, die ergebnisoffene Suche nach Wahrheit und die Möglichkeit, etablierte Deutungen von Wirklichkeit zu hinterfragen, als Bestimmungsgründe wissenschaftlichen Erkenntnisstrebens in den Hintergrund rückten.

In den Beiträgen der Jahre 2012 und 2013 wird, anders als in den früheren, weniger gewarnt, sondern öfter ein bereits als erfahrungsgesättigt verstandenes negatives Fazit gezogen. Die Wandlungen der universitären Forschung werden teils sogar fatalistisch als unumkehrbar betrachtet. Die LOM, der Wettbewerb um Drittmittel und der Publikationsdruck sind bestimmende Themen, anhand derer die Erosion des einstigen Forschungsethos festgemacht wird. Die Sorge über die Etablierung eines neuen Forschertypus, der als strategischer Unternehmer seiner Selbst agiert, also mehr an Reputation und daraus resultierendem Einkommen interessiert ist als an Erkenntnisgewinn, nimmt zu. Den Zusammenhang zwischen der Wettbewerbslogik und der Entwicklung eines solchen Wissenschaftlertypus skizziert die Politikwissenschaftlerin Zehnpfennig sehr anschaulich:

\begin{abstract}
„Drittmitteleinwerbung steht beim Prestigegewinn ganz oben auf der Liste, und so ist es zur Verbesserung der Erfolgschancen besonders ökonomisch, unabhängig von deren tatsächlicher Bedeutung modische Themen zu bearbeiten, keine riskanten Außenseiterpositionen zu beziehen, die prospektiven Gutachter nicht durch Kritik zu vergrätzen. Ein optimierter Lebenslauf erhöht die Marktchancen, und so macht es sich doch gut, als Redner auf einer wichtigen Konferenz verbucht worden zu sein, auch wenn man kurzfristig abgesagt hat, das Gespräch mit einem ausländischen Kollegen als Beweis für die Existenz eines internationalen Forschungszusammenhangs anzuführen oder einen armen kleinen Gedanken in immer wieder neuer Form zu präsentieren, um die Publikationsliste zu imposanter Größe anwachsen zu lassen.“ (Zehnpfennig, F\&L 10/2012, S. 798)
\end{abstract}

Damit beschreibt Zehnpfennig eine Anpassungsdynamik, bei der intellektuelle Risikobereitschaft und eigene Forschungsinteressen weitgehend auf der Strecke bleiben. Nicht nur eine Mainstream-Orientierung kommt hier zum Ausdruck, sondern auch ein Opportunismus, der bis zur Unredlichkeit gegenüber der Scientific Community reicht und damit wesentliche Merkmale des bis dato geltenden Forschungsethos hinter sich lässt.

Während bei Zehnpfennig noch relativ offen bleibt, ob diese Skizze eines neuen Forschertyps als Bedrohungsszenario dienen oder aber schon die von der Autorin beobachtete Wirklichkeit widerspiegeln soll, drücken andere Beiträge dezidiert Letzteres aus. So sieht der Soziologe Richard Münch (F\&L 04/2013) einen bereits erfolgten Sieg sekundärer Motive über die Wahrheits- 
suche. Mit Blick auf die Folgen der stärkeren Output-Orientierung merkt er an, dass ,das sekundäre Streben nach Anerkennung und das Wachstum um jeden Preis“ zuungunsten der „Wahrheitssuche als primäre[m] und einzig legitime[m] Interesse" (ebd., S. 269) in das Zentrum gerückt sei. Es entfalte sich, so der Titel des zugrunde liegenden Buchs von Münch, der ,akademische Kapitalismus". Mit Blick auf die Betriebswirtschaftslehre konstatieren die Fachvertreter Horst Gischer und Thomas Spengler eine fortgeschrittene Anpassung der WissenschaftlerInnen an die qua Rankings definierten und erhobenen Qualitätsmaßstäbe. Die beobachtbare Neigung, ,möglichst viele Papiere“ in als hochwertig klassifizierten Journals zu publizieren, trage zu einem Monismus hinsichtlich der Paradigmen, Theorien und Methoden bei, der dem Fach als Ganzem schade:

\begin{abstract}
„Nicht die Inhalte sind entscheidend, sondern die Publikationsorgane, in denen sie veröffentlicht wurden. Solange diese Signale für Berufungen, Drittmittel oder Zielvereinbarungen relevant werden, ist es - insbesondere für junge Akademiker - zielführend, möglichst schnell möglichst viele Papiere in ,hochwertigen“ Journalen zu platzieren. Derartiges Verhalten von Kollektiven wird häufig anhand der negativ bzw. positiv konnotierten Metaphern des Herdentriebs und der Schwarmintelligenz beschrieben. Beides ist in der ökonomischen Forschung erkennbar. Dysfunktionalitäten entstehen, wenn sich die Herde auf einen Paradigmen-, Theorien- und Methodenmonismus zubewegt und wenn einzelne Herdenmitglieder isoliert oder in die (geistige) Eremitage gedrängt werden. Intelligente Schwärme hingegen teilen sich auf, um auf diversen Wegen zum kollektiven Ziel (der Erkenntnisgewinnung) zu gelangen." (Gischer/Spengler, F\&L 11/2012, S. 905)
\end{abstract}

Obwohl immerhin noch beides - Herdentrieb und Schwarmintelligenz beobachtbar sei, verweist die Äußerung darauf, dass sich eben auch ein Forschertyp entwickelt habe, der sich am Mainstream orientiert und sich insofern vom Motiv einer Neugierde auf neue Erkenntnisse entfernt hat.

Eindeutig pessimistischer betrachtet der Erziehungswissenschaftler Norbert Seel aus der Perspektive eines kürzlich emeritierten Professors die Entwicklung in seinem Fach. Während er die Arbeit an Theorien und die Verbindung zu empirischer Forschung als „ungewöhnlich stimulierend und produktiv“ erlebt habe, beschreibt er die Gegenwart äußerst kritisch:

„Im Bereich der Forschung sehe ich seit geraumer Zeit eine starke Veränderung in Richtung Mainstream-Forschung. Ziemlich schlichte, aber einleuchtende Theorien werden aufgestellt, die dann in Hunderten kleinerer Studien untersucht werden, deren Validität mehr als fragwürdig ist. Gleiches lässt sich übrigens auch in Bezug auf die Bildungsforschung feststellen, insofern - durch die PISA-Studien angeregt 
- überall an deutschen Universitäten im Gleichklang Untersuchungen zur Bildungsqualität von Unterricht durchgeführt werden, ohne dass je eine nachhaltige Verbesserung des Unterrichts in der Schule erwartet werden darf. Da ist mittlerweile fast kein Raum mehr für andersartige und innovative Bildungsforschung, was sehr zu bedauern ist, da ich Innovation und Kreativität als Grundlagen der Wissenschaft betrachte." (Seel/Zieren, F\&L 12/2012, S. 1000)

Nicht alle ProfessorInnen äußern sich in dieser pessimistischen Weise; es überwiegt aber eindeutig die Kritik an den Leistungskriterien, die nun über Erfolg und Anerkennung bestimmten. Ein Forscherethos, bei dem Curiositas und der Wunsch nach inhaltlicher Tiefe und Breite eine wichtige Rolle spielen, stoße unter den Bedingungen von Konkurrenzdruck und Leistungskontrolle an immer deutlichere Grenzen. Letztere werden zudem als erzwungene Beschränkung eigener Freiheiten in der Gestaltung der beruflichen Aufgaben charakterisiert. Nicht allein die inhaltliche Verschiebung im beruflichen Alltag wird kritisiert, die nicht den eigenen Wünschen oder Definitionen ,guter ${ }^{6}$ Arbeit entspricht. Hinzu kommt die Wahrnehmung, durch Leistungskontrollen in einen subalternen Status versetzt worden zu sein, indem ,übergeordnete Stellen“, so der Politologe Dieter Freiburghaus, einen Kontrollanspruch geltend machen, der mitnichten abstrakt bleibt, sondern alltäglich spürbar und folgenreich ist:

„[D]er Professor [wird] zum Datenlieferanten für übergeordnete Stellen. Einen wachsenden Anteil seiner Zeit verbringt er damit, Statistiken zu erstellen, Anträge auszufüllen, Evaluationen durchzuführen, Mitarbeitergespräche zu protokollieren und gerichtsfeste Begründungen für schlechte Zensuren zu liefern. Was genau damit geschieht, bleibt ihm meist verborgen, er fühlt sich aber beobachtet und kontrolliert: ,Die Daten können jederzeit gegen Sie verwendet werden!' Man ist an den Landvermesser K. in Kafkas ,Schloss“ erinnert.“ (Freiburghaus, F\&L 11/2013, S. 912)

In den Dokumentationspflichten manifestierten sich schließlich neue Asymmetrien, die als unbotmäßige Einschränkung der Autonomie in Lehre und Forschung erfahren werden.

Konkrete Formen oder Vorschläge der Selbstbehauptung gegen diese Autonomiegefährdungen und Identitätsbedrohungen spielen in den Beiträgen indes keine große Rolle. Trotz der deutlich spürbaren Unzufriedenheit über die verschiedenen Zumutungen und Angriffe fällt das Thema eines aktiveren Widerstands unter den Tisch.

Am greifbarsten lässt sich eine Gegenwehr bei den Rankings feststellen. Zwar wurden Rankings bereits 2000/2001 kritisiert; der ,Aufruf' zum Boykott des CHE-Rankings seitens der Deutschen Gesellschaft für Soziologie reicht 
aber z. B. darüber hinaus, weil es nun darum geht, sich einer hegemonialen Bewertungsinstanz zu entziehen und eigene fachspezifische Bewertungsmaßstäbe selbstbewusst $\mathrm{zu}$ verteidigen. In seiner Begründung für die Ablehnung einer weiteren Mitwirkung am Ranking zeigt sich der damalige Vorsitzende der Fachgesellschaft, Stephan Lessenich, recht angriffslustig:

\begin{abstract}
„Denn dieses genügt erkennbar nicht den hohen Anforderungen, die sozialwissenschaftlich an einen substanziellen Vergleich universitärer Institute und Studiengänge zu stellen sind - und lässt es sich gleichwohl nicht nehmen, auf methodisch unzulänglicher Grundlage eine bewertende Sortierung derselben in eine, Spitzengruppe', ,Mittelgruppe' und ,Schlussgruppe“ vorzunehmen. ,Chuzpe', laut (ein letztes Mal!) Wikipedia ein Jiddizismus für ,eine Mischung aus zielgerichteter, intelligenter Unverschämtheit, charmanter Penetranz und unwiderstehlicher Dreistigkeit‘, dürfte noch eine eher freundliche Umschreibung dieses Vorgehens sein.“ (Lessenich, F\&L 8/2012, S. 638)
\end{abstract}

Gerade weil zugleich die grundsätzliche Bereitschaft zu einer Evaluierung des eigenen Fachs betont wird, gewinnt die Kritik am CHE-Ranking an Schärfe. Es handele sich um keine, ewig gestrige“ Berufsgruppe, die sich gegen jegliche moderne Formen der Bewertung wehrt, sondern um eine Disziplin, die - weil sie sich mit entsprechenden Methoden auskennt - auf Qualität achte:

\begin{abstract}
„Um hier von Anfang an keine falschen Vorstellungen zu bedienen: Die Soziologie wehrt sich keineswegs grundsätzlich gegen Evaluationen, sie betreibt diese vielmehr in ihren Studiengängen vor Ort alltäglich selbst und hat sich zudem schon vor Jahren als Pilotfach für das vom Wissenschaftsrat durchgeführte Wissenschaftsrating zur Verfügung gestellt. Sehr wohl wehrt sie sich aber gegen die empirisch lückenhafte und methodisch fragwürdige Erhebung durch das Centrum für Hochschulentwicklung (CHE).“(ebd.)
\end{abstract}

Darüber hinaus werden aber fast nur noch quasi , heimliche' Formen der Selbstbehauptung gegenüber Bevormundung angesprochen. So nennt Kühl (F\&L 12/2012, S. 990) die Entkopplung von Lehrplanung und konkreter Lehre, die darin bestehe, dass die Formulierung der Lehrinhalte zwar an die politischen Vorgaben angepasst werde, die Lehre in actu aber nach wie vor inhalts- bzw. erfahrungsorientiert bleibe. Damit zielt er noch nicht auf eine bewusste Unterwanderung der neuen Normen $a b$, sondern verweist lediglich auf den ein gewisses Autononomiemaß sichernden Sachverhalt, dass bei allen Restriktionen 
und Versuchen der Detailsteuerung - für die Aufgabenerfüllung nötige - Handlungsspielräume bestehen und eigene Routinen oder Deutungen der Beschäftigten zum Tragen kommen. Sieht man davon ab, bleiben einzelne Äußerungen, in denen der eigene einsame Protest gegen einen allzu hohen Kontrollanspruch ausgedrückt wird - exemplarisch hierzu der Politikwissenschaftler Ulrich von Alemann:

„[J]etzt will ein Begabtenförderungswerk für ein Promotionsstipendium einer Doktorandin von mir einen fünfseitigen Fragebogen online ausgefüllt haben, der investigativer ist als jede NSA-Ausforschung. Beispiel: ,Erläutern Sie bitte Ihre Absprachen mit Ihrem Doktoranden/Ihrer Doktorandin, um eine kontinuierliche Betreuung zu gewährleisten. Wie sichern Sie die Qualität der Betreuung ab?‘ Wollen die mich prüfen? Jetzt ist Schluss! Das mache ich nicht mehr mit. Ich habe noch ein paar andere Dinge im Leben zu tun. Ich protestiere gegen diese Gutachteritis, die jede kreative Arbeit in der Wissenschaft tötet." (von Alemann, F\&L 10/2013, S. 797)

Oder man kommt damit durch, sich auf eine Schwejksche Manier den restriktiven Anforderungen der Dokumentationspflicht zu fügen, wie es der Politikwissenschaftler Freiburghaus schildert:

„[E]inmal kam mein ,Reporting‘ mit der Bemerkung zurück, ich hätte $30 \%$ für Forschung eingesetzt, ein Jahr zuvor jedoch $35 \%$; dies sei zu begründen. Ich antwortete, ich hätte mich leider vertippt, der Prozentsatz sei derselbe geblieben. Damit war man zufrieden. Solche Zahlen werden dann ,nach oben` weitergeleitet, aggregiert, ausgewertet und dienen fortan als Grundlage für die Wissenschaftspolitik.“" (Freiburghaus, F\&L 11/2013, S. 912)

\subsection{Fensterreden und Arbeitsalltag}

Insgesamt zeigt unsere Nachzeichnung der medialen Auseinandersetzung auf der einen Seite: Das Bild der Universitätsreformen, das sich die JournalistInnen gemacht haben, ist im Zeitverlauf differenzierter geworden. Die großen Hoffnungen, die in die Reformen gesetzt wurden, sind nicht falsifiziert worden, haben aber eine Beimischung an Nachdenklichkeit erfahren: Vielleicht war nicht alles gut - womöglich war manches in der verabreichten Dosis nicht gut - und eventuell waren die Rahmenbedingungen, unter denen manche Maßnahmen 
eingeführt wurden, nicht gut. Dass die Reformen aber grundsätzlich erforderlich sind: Diese Einstellung hat sich nicht verändert.

Auf der anderen Seite ist festzustellen: Die öffentlichen Äußerungen der ProfessorInnen sind im Vergleich zur Sichtweise der JournalistInnen viel konstanter geblieben, haben sich im Zeitverlauf sogar verfestigt. Das Gegenteil an Nachdenklichkeit über die eigene Position ist eingetreten: Man fühlt sich in den Befürchtungen, die am Anfang der Reformen geäußert wurden, durch deren Umsetzung nur bestätigt.

Der mediale Diskurs, in dem beide Seiten einander immer wieder herausgefordert haben, hat somit eine klare Frontstellung hervorgebracht. Ohne bewerten zu müssen, welcher der Standpunkte realitätsadäquater ist, können wir hier mit Blick auf unsere Untersuchungsfrage feststellen: Aus dieser Diskurskonstellation ergeben sich für die ProfessorInnen zwei Arten von Bedrohungen ihrer beruflichen Identität. Die eine rührt daher, dass sie weiterhin, wenn auch nicht mehr so auftrumpfend wie in den Anfangsjahren, öffentlich als Verweigerer einer als dringend erforderlich deklarierten Reform der deutschen Universitäten gebrandmarkt werden: Was schief läuft, liegt in hohem Maße an ihnen. Die andere Identitätsbedrohung ergibt sich aus dem neuen ,homo academicus oeconomicus" (Peter 2010), der als vorgebliches Erfolgsmodell aus den Reformen hervorgehen soll: Wer dieses Modell ignoriert, dem kann vorgehalten werden, seiner ProfessorInnenrolle nicht länger gerecht zu werden. In dem Maße, in dem Reformverweigerer mit leibhaftigen VertreterInnen dieses Erfolgsmodells konfrontiert werden können, spitzt sich für erstere die Identitätsbedrohung noch zu. Man kann sie als ,Ewiggestrige“ brandmarken.

Was tun ProfessorInnen angesichts solcher Identitätsbedrohungen? Auf diese Frage geben deren mediale Stellungnahmen, die auf journalistische Provokationen reagieren, nur entsprechend patzige ,Widerworte'. Will man wissen, wie ProfessorInnen tatsächlich damit umgehen, womit sie die Universitätsreformen konfrontieren, muss man über die öffentlichen Fensterreden hinaus auf den tagtäglichen Arbeitsalltag, das Erleben der je eigenen Lehr- und Forschungsbedingungen und die daraus hervorgehenden Praktiken des Lehrens und Forschens schauen. Sind die Identitätsbedrohungen wirklich so gravierend, wie es die medialen Stellungnahmen der ProfessorInnen zum Ausdruck bringen? Und insoweit es sich um nicht ignorierbare Identitätsbedrohungen handelt: Welche Praktiken der Identitätsbehauptung stehen den ProfessorInnen dagegen zur Verfügung? 


\section{Anhang Kapitel 2: Zitierte Medienartikel}

Je Printmedium in chronologischer Reihenfolge

\section{DER SPIEGEL}

1999

Dahlkamp, Jürgen, Florian Gless, Almut Hielscher, Joachim Mohr, Bettina Musall, Irina Repke, Andrea Stuppe und Hans-Jörg Vehlewald: „Um Studenten kämpfen“, SPIEGEL 15/1999, S. 59-67.

Dahlkamp, Jürgen: „Ein Drittel Daimler, ein Drittel Bosch“, SPIEGEL 15/1999, S. 98-101.

Klein, Stefan: „So schön übersichtlich“, SPIEGEL 15/1999, S. 86-89.

Stegelmann, Katharina: „Störfaktor Student“, SPIEGEL 24/1999, S. 56-60.

Mohr, Joachim: „Geld für die Guten“, SPIEGEL 36/1999, S. 114-115.

Stoldt, Hans-Ulrich: „Subtiler Druck“, SPIEGEL 43/1999, S. 76.

2000

Koch, Julia, Joachim Mohr, Mathias Müller von Blumencron, Padma Rao, Michael Sauga, Michael Schmidt-Klingenberg, Hilmar Schmundt, Hajo Schumacher: „Ausfall im System“, SPIEGEL 13/2000, S. 40-61.

Koch, Julia und Joachim Mohr: „Kohle für Koryphäen“, SPIEGEL 16/2000, S. 34.

Mohr, Joachim: „Studieren lohnt sich“, SPIEGEL 46/2000, S. 54-62.

\section{1}

Neubacher, Alexander: „Headhunting mit Taschenlampe“, SPIEGEL 4/2001, S. 144.

Feldenkirchen, Markus und Joachim Mohr: „Im Schneckentempo zum Diplom“, SPIEGEL 12/2001, S. 60-64.

Stegelmann, Katharina: „Neue Freiheit“, SPIEGEL 33/2001, S. 50-51.

2010

Darnstädt, Thomas: „Siemens statt Humboldt“, SPIEGEL 28/2010, S. 40-45.

o. A.: „Bildungswüste Deutschland“, SPIEGEL 35/2010, S. 18. 


\section{2}

Bartsch, Matthias und Jan Friedmann: „W wie wenig“, SPIEGEL 07/2012, S. 46.

o. A.: Professorengehälter - Globaler Trend, SPIEGEL 8/2012, S. 19.

Friedemann, Jan: „Blau wie blöd“, SPIEGEL 49/2012, S. 50.

\section{DIE ZEIT (o. S.)}

1999

Spiewak, Martin: „Zuhause in zwei Welten“, DIE ZEIT15/1999. https://www. zeit.de/1999/15/Zu_Hause_in_zwei_Welten.

Spiewak, Martin: „Ein akademischer Raufbold“, DIE ZEIT 29/1999. https:// www.zeit.de/1999/29/199.929.reformer_herrman.xml.

Hoffmann, Wolfgang: „Den Muff aus den Talaren“, DIE ZEIT 36/1999. https://www.zeit.de/1999/36/199.936.kolumne.xml.

Spiewak, Martin: „Überforderte Fachidioten“, DIE ZEIT 46/1999. https:// www.zeit.de/1999/46/199.946.c-med-staudt_.xml/komplettansicht.

\section{0}

Spiewak, Martin: „Feindliche Übernahme“, DIE ZEIT 08/2000. https://www. zeit.de/2000/08/200.008.c-fachhochschule.xml.

Etzold, Sabine: „Humboldts letzter Krieger“, DIE ZEIT 14/2000. https://www. zeit.de/2000/14/200.014.hvb_.xml.

Kerstan, Thomas: „Die Volks-Hochschule“, DIE ZEIT 14/2000. https://www. zeit.de/2000/14/200.014.hochschule_.xml.

Löer, Wigbert: „Mut zur Meinung“, DIE ZEIT 22/2000. https://www.zeit. de/2000/22/200.022.c-politologen_.xml.

\section{1}

Spiewak, Martin: „Zweite Wahl“, DIE ZEIT online 22.03.2001. https://www. zeit.de/2001/13/hochschulreform_20010327.xml.

Spiewak, Martin: „Bulle wider Bulmahn“, DIE ZEIT 14/2001. https://www. zeit.de/2001/14/200114_2._leiter.xml.

Etzold, Sabine: „Ein Gesetz genügt nicht“, DIE ZEIT 40/2001. https://www. zeit.de/2001/40/Ein_Gesetz_genuegt_nicht.

Spiewak, Martin: „, Coach für die erste Liga“, DIE ZEIT 45/2001.https://www. zeit.de/2001/45/Coach_fuer_die_erste_Liga. 


\section{9}

Jan-Martin Wiarda: „Streikbilanz“, DIE ZEIT 53/2009https://www.zeit. de/2009/53/C-Seitenhieb.

\section{2}

Wiarda, Jan-Martin: „Unterbezahlte Profs“, DIE ZEIT 08/2012. https://www. zeit.de/2012/08/Professoren-Bezahlung.

Wiarda, Jan-Martin: „Abgeschreckt“, DIE ZEIT 22/2012. https://www.zeit. de/2012/22/C-Ingenieurstudenten/komplettansicht.

Etscheit, Georg: „Die Superprofs“, DIE ZEIT 44/2012.https://www.zeit. de/2012/44/Universitaeten-Didaktik-Lehren-Dozenten-Studenten.

\section{3}

Spiewak, Martin: „Nichts dazu gelernt“, DIE ZEIT 07/2013. https://www.zeit. de/2013/07/Selbstreflexion-Unis-Annette-Schavan-Doktortitel.

Schmidt, Marion und Martin Spiewak: „Die fetten Jahre sind vorbei“, DIE ZEIT 25/2013. https://www.zeit.de/2013/25/wissenschaft-finanzierung-reform. Etzold, Sabine: „Abschied von der Elite“, DIE ZEIT 31/2013. https://www. zeit.de/2013/31/exzellenz-unis-foerderung-kommentar.

Kohlenberg, Kerstin und Yassin Musharbash: „Die gekaufte Wissenschaft“, DIE ZEIT 32/2013. https://www.zeit.de/2013/32/gekaufte-wissenschaft.

Sentker, Andreas: „Die Nobelpreise von morgen“ DIE ZEIT 42/2013. https:// www.zeit.de/2013/42/nobelpreise-forschung-usa-deutschland?print.

Daum, Matthias: „Die gekaufte Uni“, DIE ZEIT 49/2013.https://www.zeit. de/2013/49/universitaet-zuerich-ubs.

\section{Forschung \& Lehre}

\section{0}

Fischer, Klaus: „Die verborgenen Quellen des Neuen. Kreativität und Planung im wissenschaftlich-technischen Fortschritt“, F\&L 1/2000, S. 14-18.

Stemmler, Theo: „Über den Morbus utilitaris. Fabelhafter Bericht an eine Akademie“, F\&L 2/2000, S. 84-85.

Ronge, Volker: „Zielvereinbarungen. Contra“, F\&L 4/2000, S. 189.

Schüren, Peter: „Kleine Münze - Große Leistungen? Motivation in der Wissenschaft", F\&L 5/2000, S. 232-234. 
Hoeren, Thomas in: „Stimmen zur Expertenkommission“, F\&L 6/2000: S. 296-297.

DHV: „Deutscher Nobelpreis und immaterielle Anreize. Positionspapier des DHV zum Bericht der Expertenkommission“, F\&L 7/2000, S. 350-351.

Morkel, Arnd: „Theorie und Praxis. Die Aufgabe der Universität“, F\&L 8/2000, S. 396-398.

Wörner, Johann-Dietrich: „Akkreditierung - freiwilliger Akt der Hochschule. Fragen an den Vorsitzenden des Akkreditierungsverbundes für Ingenieurstudiengänge“, F\&L 10/2000, S. 510-511.

Neuhäuser, Rudolf: „Die Universitäten zwischen Skylla und Charybdis? Das Beispiel der österreichischen Universitäten“, F\&L 11/2000, S. 587-590.

Meincke, Jens Peter: „Universitäten und Fachhochschulen. Eine Ortsbestimmung“, F\&L 12/2000: S. 631-634.

\section{1}

Schiedermair, Hartmut: „Menschenwürde - Thema der Zukunft. Über die Entstehung des Neuen in der Wissenschaft", F\&L 5/2001, S. 235-239.

\section{2}

anonym: „Freiheit und Ungebundenheit. Rückblick eines Emeritus“, F\&L 2/2012, S. 116.

Kühl, Stefan: „Der Sudoku-Effekt. Die Komplexitätsexplosion an den Hochschulen“, F\&L 4/2012, S. 290-293.

Loer, Thomas: „Not macht erfinderisch - aber nicht in der Wissenschaft. Über die Situation der Privatdozenten und zwei Modelle von Universität“, F\&L 4/2012, S. 288-289.

Dieter Lenzen: „Hochschulen sind keine Fertigungsstraßen. Neun provokative Anmerkungen zum Bologna-Prozess“, F\&L 5/2012, S. 356-358.

Lessenich, Stephan: „Ausstieg aus dem CHE-Ranking? Pro: Stephan Lessenich, Contra: Frank Ziegele“, F\&L 8/2012, S. 638-639.

Ludwig-Mayerhofer, Wolfgang: „Kein Abschied von Bologna“, F\&L 10/2012, S. 785 .

Zehnpfennig, Barbara: „Wie ökonomisch ist Bildung? Ein unzeitgemäßer Einspruch“, F\&L 10/2012, S. 796-798.

Odendahl, Kerstin: „Zeit für ein Umdenken. Die Europäisierung der Bildungssysteme“, F\&L 11/2012, S. 880-882. 
Gischer, Horst und Thomas Spengler: „Ergebnis und Erkenntnis in der Erfahrungswissenschaft. Ökonomische Forschung zwischen Schwarmintelligenz und Herdenverhalten“, F\&L 11/2012, S. 904-905.

Kühl, Stefan: „Modell Sprachschule. Die Effekte der neuen Mode der Kompetenzorientierung an den Hochschulen“, F\&L 12/2012, S. 988-990.

Seel, Norbert und Klaus Zierer: ,Familie und Schlangengrube. Die Universität aus der Perspektive unterschiedlicher Generationen“, F\&L 12/2012, S. 1000_ 1002.

\section{3}

Bayer, Klaus: „Immer bessere Noten? Über die Zerstörung der geisteswissenschaftlichen Prüfungskultur", F\&L 1/2013, S. 36-38.

Kamphausen, Georg: „Einsamkeit und Freiheit. Wer verteidigt die Leitidee der Institution Universität?“, F\&L 2/2013, S. 114-117.

Lottes, Günther: „Die politische Klasse in der Gelehrtenrepublik. Über Erkenntnisdrang, Wissensweitergabe und Macht“, F\&L 2/2013, S. 128-129.

Münch, Richard: „Vermehrung statt Erneuerung? Das Wachstum in der Wissenschaft“", F\&L 4/2013, S. 268-270.

von Alemann, Ulrich: „Jetzt ist Schluss!“, F\&L 10/2013, S. 797.

Freiburghaus, Dieter: „Im Gehäuse der Hörigkeit. Ein Kommentar zur Bürokratie“, F\&L 11/2013, S. 912-913.

Kastl, Jörg Michael: „Neue Steuerung. Anmerkungen zum geplanten Landeshochschulgesetz in Baden-Württemberg“, F\&L 12/2013, S. 996-998.

\section{Literatur}

Feil, Michael, Lisa Tillmann, und Ulrich Walwei. 2008. Arbeitsmarkt- und Beschäftigungspolitik nach der Wiedervereinigung. Zeitschrift Für Sozialreform 54 (2): 161-186.

Kaldewey, David. 2015. Die responsive Struktur der Wissenschaft. Ein Kommentar. In Die Responsivität der Wissenschaft - Wissenschaftliches Handeln in Zeiten neuer Wissenschaftspolitik, Hrsg. Hildegard Matthies, Dagmar Simon, und Marc Torka, 209-230. Bielefeld: Transcript.

Liebeskind, Uta. 2011. Universitäre Lehre - Deutungsmuster von ProfessorInnen im deutsch-französischen Vergleich. Konstanz: UVK.

Maasen, Sabine, und Sacha Dickel. 2016. Partizipation, Responsivität, Nachhaltigkeit Zur Realfiktion eines neuen Gesellschaftsvertrags. In Handbuch Wissenschaftspolitik, Hrsg. Dagmar Simon, Andreas Knie, Stefan Hornbostel, und Karin Zimmermann, 225242. Wiesbaden: Springer VS. 
Peter, Lothar. 2010. Der Homo academicus-oeconomicus. In Diven, Hacker, Spekulanten Sozialfiguren der Gegenwart, Hrsg. Stephan Moebius und Markus Schroer, 206-218. Berlin: Suhrkamp.

Torka, Marc. 2015. Responsivität als Analysekonzept. In Die Responsivität der Wissenschaft - Wissenschaftliches Handeln in Zeiten neuer Wissenschaftspolitik, Hrsg. Hildegard Matthies, Dagmar Simon, und Marc Torka, 17-50. Bielefeld: Transcript.

Open Access Dieses Kapitel wird unter der Creative Commons Namensnennung 4.0 International Lizenz (http://creativecommons.org/licenses/by/4.0/deed.de) veröffentlicht, welche die Nutzung, Vervielfältigung, Bearbeitung, Verbreitung und Wiedergabe in jeglichem Medium und Format erlaubt, sofern Sie den/die ursprünglichen Autor(en) und die Quelle ordnungsgemäß nennen, einen Link zur Creative Commons Lizenz beifügen und angeben, ob Änderungen vorgenommen wurden.

Die in diesem Kapitel enthaltenen Bilder und sonstiges Drittmaterial unterliegen ebenfalls der genannten Creative Commons Lizenz, sofern sich aus der Abbildungslegende nichts anderes ergibt. Sofern das betreffende Material nicht unter der genannten Creative Commons Lizenz steht und die betreffende Handlung nicht nach gesetzlichen Vorschriften erlaubt ist, ist für die oben aufgeführten Weiterverwendungen des Materials die Einwilligung des jeweiligen Rechteinhabers einzuholen.

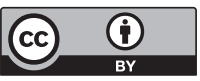

